This document is confidential and is proprietary to the American Chemical Society and its authors. Do not copy or disclose without written permission. If you have received this item in error, notify the sender and delete all copies.

\title{
Soft Photocatalysis: Organic Polymers for Solar Fuel Production
}

\begin{tabular}{|r|l|}
\hline Journal: & Chemistry of Materials \\
\hline Manuscript ID & cm-2016-01894f.R2 \\
\hline Manuscript Type: & Perspective \\
\hline Date Submitted by the Author: & n/a \\
\hline Complete List of Authors: & $\begin{array}{l}\text { Vyas, Vijay; Max Planck Institute for Solid State Research } \\
\text { Lau, Vincent Wing-Hei; Max Planck Institute for Solid State Research, } \\
\text { Lotsch, Bettina; Max Planck Institute for Solid State Research, }\end{array}$ \\
\hline
\end{tabular}

SCHOLARONE ${ }^{\text {m }}$

Manuscripts 


\section{INTRODUCTION}

Global energy demands continue to soar due to growing population and increasing industrialization. With limited reserves of fossil fuels and rising environmental concerns, the conversion of solar energy into clean transportable fuels such as hydrogen or methanol is the key to sustainable growth. Since Honda and Fujishima's seminal report ${ }^{1}$ on hydrogen evolution from a $\mathrm{TiO}_{2}$ photoanode in the 1970s, materials research into novel photocatalysts has reached almost every corner of the periodic table of elements. Some state-of-the-art developments include sacrificial systems with quantum efficiencies approaching $100 \%{ }^{2,3}$ or photocatalytic composites capable of water splitting at up to $2 \%$ efficiency. ${ }^{4,5}$ These rapid advances show that the US Department of Energy's (DoE) current target of $10 \%$ solar to hydrogen conversion efficiency ${ }^{6}$ is not only a desirable but also a feasible goal in photocatalysis research. Despite the research progress thus far, meeting the DoE cost target ${ }^{6}$ of $\$ 2.10 \mathrm{~kg}^{-1}$ for commercial deployment still requires significant improvements in terms of photocatalytic efficiency, stability, and cost. ${ }^{7-9}$ Following Honda and Fujishima's work, there has been significant focus on inorganic photocatalysts, particularly the metal oxides and chalcogenide semiconductors and modifications thereof (e.g. incorporation of dopants, formation of solid solutions, assembling composites etc; see the comprehensive reviews by Yang et $a l^{\circ}$ and Osterloh et $a l^{11}$ for example), since they combine high photocatalytic activity with chemical stability, though they are disadvantaged by limited variability. In contrast, organic or metal complex-based homogeneous photocatalysts offer molecular customizability to tune their optoelec- tronic properties, activity and selectivity. ${ }^{12}$ Furthermore, their homogeneity enables unambiguous characterization to better understand the catalytic processes and redox mechanisms involved, which may be translated into rational catalyst design. However, the tunability of molecular photocatalysts comes at the expense of low stability, challenging synthesis routes, and difficulty in scalability. A promising compromise between the two is the heterogenization of homogeneous photocatalysts by incorporating the functional molecules within a robust matrix. ${ }^{13}$ This strategy - in its original conception from the field of conventional (thermal) catalysis ${ }^{14,15}$ - can afford highly active and synthetically tunable "single-site" catalysts which are molecular in nature, but come with the benefits of heterogeneous catalysts, including ease of separation (and therefore recyclability) and improved photophysical properties, and, in many cases, can confer improved chemical and thermal stability. Such polymeric or "soft" materials also benefit from properties such as being light weight, inexpensive and earth-abundant, facilely synthesized, and of relatively low toxicity.

This perspective will provide an overview of the emerging field of polymer photocatalysis, which has its roots in the 1980 os and finds its most prominent representatives in $1 \mathrm{D}$ and ${ }_{2} \mathrm{D}$ carbon nitride polymers based on triazine and heptazine units. Owing to their strictly alternating $\mathrm{C}-\mathrm{N}$ backbones without any $\mathrm{C}-\mathrm{C}$ or $\mathrm{C}-\mathrm{H}$ bonds and their resulting electron deficient character, carbon nitride polymers are distinct from classical organic polymers in both their molecular structures, as well as chemical behavior. After briefly surveying the key advances and challenges in carbon nitride chemistry, we will turn to the more general 
and less explored class of organic photocatalysts which are composed of polymerizable organic monomers, resulting in $\mathrm{C}-\mathrm{C}$ bonded, mostly $\pi$-conjugated polymer backbones. First demonstrated in 1985 for light-induced solar fuel synthesis, the one-dimensional, $\pi$-conjugated polymers have since progressed to increasing topological complexity in terms of dimensionality ( $1 \mathrm{D}$ vs $2 \mathrm{D}$ vs ${ }_{3} \mathrm{D}$ ) and structural perfection (amorphous vs crystalline), thereby setting the stage for an emerging class of molecularly editable organic frameworks for photocatalysis (Scheme 1). This account will be devoted to photocatalysis for solar fuel production only; light-assisted organic transformations subsumed under the term photoredoxcatalysis $^{16-21}$ will only be discussed at places central to the photocatalytic system under study.

\section{POLYMERS AS PLATFORMS FOR PHOTOCATALYSIS: DESIGN STRATEGIES}

Engaging organic polymeric materials for solar fuel synthesis offer a range of benefits. ${ }^{22,23}$ As efficient light capture by the photocatalyst is a primary step in the photocatalytic process, organic chromophores, used as building blocks, provide a virtually unlimited variety of optoelectronic and photophysical properties that can be translated into the polymer, including high absorption cross section in the visible range and variable optical bandgaps, high charge carrier mobilities ( $\mathrm{n}$ - and $\mathrm{p}$-type) and long-lived excited states. These properties can further be refined by choosing suitable combinations of building blocks and adjusting their ratios or as a function of the degree of polymerization.

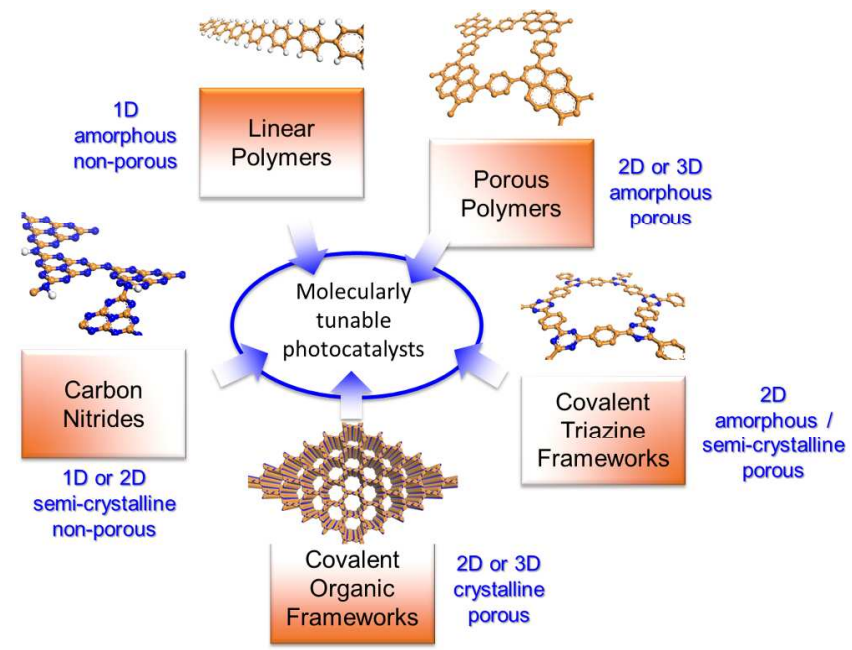

Scheme 1: Overview of the different classes of polymeric photocatalysts derived from molecularly tunable building blocks, which are discussed in this perspective.

Following the harvesting of photons with energies equal to or exceeding the optical bandgap of the photocatalyst, electrons are excited from the valence band into the conduction band, leaving behind electron holes (Scheme 2). The electron - hole pairs (excitons) thus formed may separate into polaron pairs (e.g., within $\approx$ 200 fs for carbon nitride polymers ${ }^{24}$ ) and need to be sufficiently long lived to effectively diffuse to the catalyst surface where redox processes leading to water splitting or $\mathrm{CO}_{2}$ reduction take place. Interfacial charge transfer for these reactions in the prototypical inorganic system $\mathrm{TiO}_{2}$ takes place in the micro- to millisecond timescale. ${ }^{25}$

Choosing building blocks with inherently high charge carrier mobilities and extending the conjugation length of the polymer is expected to improve exciton/polaron migration along the polymer chain or plane. Notably, $\pi$ stacking in $2 \mathrm{D}$ polymers can significantly enhance interplanar charge migration, thus providing an additional charge percolation channel perpendicular to the layers. ${ }^{26}$ Inherently micro- or mesoporous polymers can form bicontinuous donor - acceptor architectures (heterojunctions) where the host (i.e., the framework) and guest (i.e., a species contained in the pores) are phase-separated on the nanometer scale, which is expected to facilitate charge separation and to induce proximity effects relevant for catalysis. This makes porous $2 \mathrm{D}$ and $3 \mathrm{D}$ polymers particularly attractive, and even more so if ordered charge percolation pathways and heterojunction architectures are accessible, as for example in crystalline covalent organic frameworks (COFs, see 2.6).

Ordered porosity can also be an asset when it comes to the catalytic conversion. Typically, a metal co-catalyst is used to reduce the kinetic overpotential for the redox process involved, and enabling efficient charge transfer from the polymer to the catalytic site is the key to prevent recombination of the charge carriers and to facilitate substrate conversion. Introducing - through non-covalent or covalent bonding - the co-catalyst into the pores of high internal surface area polymers may therefore be an efficient means to increase catalyst loading and to preconcentrate the substrate or sacrificial agents.

A wealth of information regarding the photophysics and redox catalysis is already available from the research on organic photovoltaics (OPV) on the one hand, ${ }^{27}$ and molecular photocatalysts containing metal coordination complexes, dyes, dyads and triads on the other hand. ${ }^{28}$ We expect that findings from these fields will radiate out into polymer photocatalysis and can be conveniently adapted to the rational design of new polymeric heterogeneous photocatalysts with engineered photophysical and catalytic properties. 


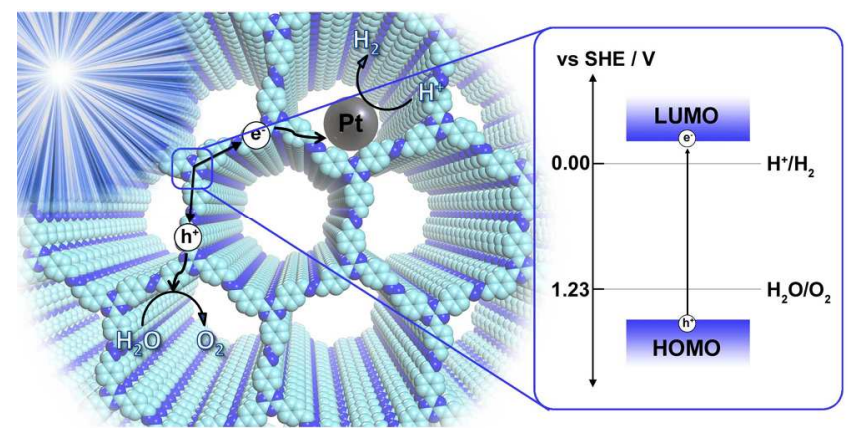

Scheme 2: Schematic overview of the photocatalytic processes in an idealized $2 \mathrm{D}$ layered polymeric photocatalyst with simplified eclipsed representation of the stacking of individual layers.

\subsection{Carbon nitrides}

This section is not meant to provide a comprehensive overview of the ever-growing field of carbon nitride photocatalysis, and the reader is referred to a number of excellent reviews on this topic instead. ${ }^{29}, 3^{\circ}$ Rather, we intend to pinpoint some of the research lines in carbon nitride chemistry that have led up - both causally and in parallel - to the emerging field of polymer photocatalysis, and to highlight differences and commonalities between the two. Widespread interest in graphitic carbon nitride (g- $\mathrm{C}_{3} \mathrm{~N}_{4}$ ) first arose in the $1990 \mathrm{os}$ as it was considered to be the precursor to the hypothetical $3 \mathrm{D} \beta$ - and cubic phases of binary carbon nitride, $\mathrm{C}_{3} \mathrm{~N}_{4}$, which computationally have been predicted to have ultra-high hardness. ${ }^{31,}{ }^{32}$ While $\mathrm{g}-\mathrm{C}_{3} \mathrm{~N}_{4}$ has not been unambiguously synthesized in bulk amounts and there is an ongoing controversy as to the chemical nature of "graphitic carbon nitride", interest in these materials is enjoying a resurgence following the seminal work of Antonietti, Domen and co-workers, ${ }^{33-35}$ who demonstrated that a heptazine-based polymer can photocatalyze each of the two half reactions of watersplitting in the presence of sacrificial agents. The material used in this work, christened "melon" in the 1830 sy Berzelius and Liebig, ${ }^{36,37}$ is now synonymously called "graphitic carbon nitride" or " $\mathrm{g}-\mathrm{C}_{3} \mathrm{~N}_{4}$ " in the current literature. We will therefore use the terms melon and $g-C_{3} N_{4}$ interchangeably to maintain consistency in this field. The structure of melon remained elusive for over 150 years since its first synthesis, as its amorphous nature and lack of solubility hamper structural characterization. The structure of crystalline melon has only been solved recently using a combination of spectroscopic methods, electron diffraction, and structural modelling. Together, they reveal that melon consists of heptazine units linked by secondary amines into one-dimensional polymer strands, which are hydrogen-bonded into arrays that stack together as in layered materials (Figure 1, left).$^{38,} 39$ This structural model was also found by Tyborski et al. to fit best to the powder x-ray diffraction pattern. ${ }^{40}$ Results from neutron diffraction and pair distribution function analysis also provide experimental support for this $1 \mathrm{D}$ polymeric structure. ${ }^{41}$ More recently, a triazine based $2 \mathrm{D}$ polymer, poly(triazine imide), PTI (structure shown in Figure 1, right), was developed by ionothermal synthesis in salt melts at temperatures beyond $500^{\circ} \mathrm{C}$, which was shown to be photocatalytically active for the hydrogen evolution reaction..$^{42-48}$

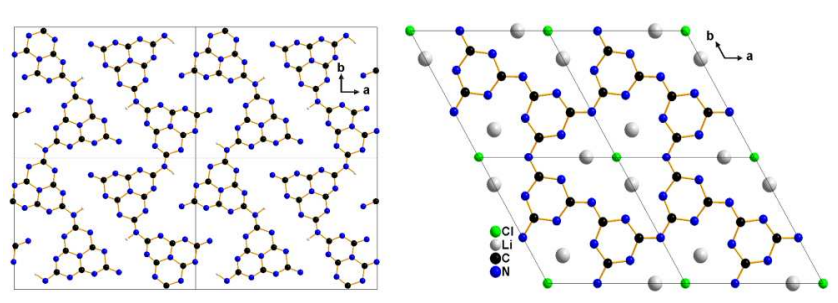

Figure 1: Crystal structures of melon (left) and PTI (right) viewed along the c-axis. ${ }^{38,49}$

The research interest in these materials stems from its many advantageous properties for photocatalytic solar fuel production, including: 1) suitable electronic structures and band positions, which straddle the redox potential for water reduction and oxidation while having an optical gap sufficiently narrow for visible light harvesting; 2) excellent chemical and thermal stability, and 3) ease of synthesis from inexpensive, earth-abundant precursors. Carbon nitrides however suffer from severe draw backs, such as 1) limited chemical diversity, i.e. the limited number of building blocks available (triazine and heptazine) and their lack of reactivity; and 2) the low rate of photocatalytic hydrogen and especially oxygen evolution, which is alleviated in part by the use of noble-metal cocatalysts and sacrificial electron donors or acceptors. The moderate activities of unmodified carbon nitrides are attributed to fast exciton relaxation ${ }^{50}$ and inefficient charge transfer, which is amplified by their generally low intrinsic surface areas. ${ }^{5^{1}}$ The strategies taken to improve these limitations generally fall under three categories: 1) co-polymerization for modulating the optoelectronic properties such as light harvesting, 52, 53 2) composite/hybrid formation for exciton separation, ${ }^{54}$ and 3 ) texturization to increase the number of reactive sites. ${ }^{51,55}$, ${ }^{56}$ More recently, an increasing trend towards replacement of noble metal co-catalysts with homogeneous and bioinspired systems is noticeable, which is driven by the need to better understand the photocatalytic mechanism, and to reduce the overall cost of the system, ${ }^{57^{-60}}$ In fact, quantum efficiencies of $26 \%$ under sacrificial conditions have been attained for a carbon nitride synthesized by the self-templating precursor urea. ${ }^{61}$ Other promising systems in terms of activity, earth abundance, and scalability prepared through judicious selection of the co-catalyst have also been reported. Prominent examples include g$\mathrm{C}_{3} \mathrm{~N}_{4}$ paired with carbon nanodots ${ }^{4}$ or a combination of cobalt oxide and platinum, ${ }^{5}$ both of which exhibit complete water-splitting without the use of sacrificial agents. Despite these successes, the lack of synthetic flexibility and control over polymer size, composition and defect levels hinders their photocatalytic improvement, e.g. by 
modulation of their intrinsic optoelectronic properties through modifying the bandgap, carrier localization, or the electrochemical driving force for hydrogen evolution. As an example, we and others have shown that the optical gap and orbital energies (thermodynamics), as well as the availability of reactive sites (kinetics), are dependent on the number of heptazine units in the polymer; in turn, all these properties affect the observed photocatalytic activity. ${ }^{62,63}$ Examination of how each feature affects the macroscopic properties, including photocatalytic activity, is challenging given that one cannot systematically vary the polymer size in carbon nitrides through bottom-up synthetic chemistry; in fact, even the structure of the prototype carbon nitride photocatalysts is typically ill-defined. These drawbacks thus highlight the need of using welldefined, synthetically flexible systems, such as the polymers and frameworks discussed in the following.

\section{$2.2 \pi$-Conjugated linear polymers}

Although a new and rapidly emerging field at first sight, polymer photocatalysis has its roots in the early 1980s, when in the aftermath of the global oil crisis the daunting challenge of solar fuel generation by sustainable materials was recognized. In their seminal work, Yanagida and coworkers demonstrated $\mathrm{H}_{2}$ evolution photocatalyzed by an organic semiconductor in sacrificial systems for the first time. ${ }^{64}$ Poly- $p$-phenylene (PPP; Figure 2 ), synthesized by $\mathrm{Ni}$-catalyzed cross-coupling of 1,4-dibromobenzene or 4,4'-dibromobiphenyl, reduces water in the presence of amines as sacrificial electron donors. Further analysis of the structure of the polymer showed that, depending on the residual bromine content, the average length of a polymer chain was between 7 and 11 phenylene units (hence termed PPP-7 and PPP-11, respectively). With a bandgap of $2.9 \mathrm{eV}$, which was found to be largely independent of the polymer chain length as determined by photoacoustic spectroscopy, PPP-11 shows a hydrogen evolution rate of $2.1 \mu \mathrm{mol} \mathrm{h} \mathrm{h}^{-1}$ using diethylamine as sacrificial electron donor (see also Table 1 ). It is of note that PPP powder synthesized from benzene according to the Kovacic ${ }^{65}$ method was photocatalytically inactive under similar conditions. This may hint to the active role residual Ni metal, introduced through the cross-coupling reaction, could play as a cocatalyst. In fact, while apparent quantum efficiencies (AQEs) of $<0.04(\lambda>290 \mathrm{~nm})$ were recorded for the assynthesized polymer, the use of photodeposited colloidal noble metal co-catalysts such as ruthenium dramatically improves the rate by a factor of 9 when compared with unloaded PPP in methanolic trimethylamine solution under full spectrum irradiation, yielding an $\mathrm{AQE}_{\max }$ of 0.015 at $\lambda=405 \mathrm{~nm} .{ }^{66}$ Nevertheless, nonmetallized PPP was found to more efficiently photocatalyze the reduction of carbonyl compounds and electron-deficient olefins by triethylamine (TEA) in methanol as compared to Ru-loaded PPP. Notably, for example, the reduction of methyl benzoylformate to methyl mandelate in the presence of PPP-11 proceeded in $78 \%$ yield without the formation of other reduction products after a $3 \mathrm{~h}$ irradiation period. ${ }^{66}$ The authors rationalize the ob- served photocatalytic activity by the chain geometry of PPP which upon photoexcitation may form a quinoid-like substructure giving rise to intra- or intermolecular charge-separated states aiding charge transfer to or from the polymer backbone. However, the low density of the polymers suggests out-of-plane twisting of the $p$ phenylene chains, thereby giving rise to an increase in the ionization potential with increasing chain length. This may assist charge carrier localization in solid PPP and, concomitantly, give rise to a contribution of electrons existing in excitonic states rather than from free electrons in the conduction band. ${ }^{66}$

Heteroatom substitution is known to reduce the bandgap, hence improving the light harvesting ability of a photocatalyst. A linear polymer containing pyridyl units (PPy; Figure 2) was synthesized by Ni-catalyzed Yamamoto coupling of 2,5-dibromopyridine. Compared to an optical gap of $2.9 \mathrm{eV}$ in PPP, PPy shows a reduced bandgap of $2.4 \mathrm{eV}^{67}$ This observed red shift in the absorption spectra of PPy coupled with better photoinduced charge separation, results in an almost 10-fold enhancement for hydrogen evolution by PPy under visible light irradiation $(>400 \mathrm{~nm}$ ) compared to PPP. The rate of photocatalysis was improved further by a factor of 14 in the presence of colloidal $\mathrm{Ru}$ as co-catalyst. ${ }^{68}$ Interestingly though, the observed products of the photoreduction of carbonyl compounds suggests that a sequential two-electron transfer reduction is operative in PPy, rather than the oneelectron pathway observed for PPP.

The authors reason that the photoexcited state in PPy is reductively quenched by the sacrificial electron donor, hence resulting in the formation of an anion radical which is better stabilized by the pyridine rings (Scheme 3) as compared to the phenyl rings in PPP. The PPy structure is expected to be more co-planar than the PPP backbone owing to the smaller steric hindrance between the hydrogen atom at the 6-positions and the nitrogen atom of the neighboring pyridine ring. It is this coplanar geometry in PPy that should stabilize, through delocalization, the radical anion that is formed upon reductive quenching with an electron donor (Scheme 3; P, Q and R). In addition, the authors present evidence for the formation of a hydrogenated PPy intermediate occurring through a photo-Birch reduction (Scheme 3; A, B, C and D), which may play an important role in the photoreduction of ketones with very negative reduction potentials. In other words, two different photoreduction mechanisms may be at play in PPy, the dominance of which depends on the reduction potential of the involved substrate, namely direct electron reduction via radical anion or bipolaron states (Scheme 3; P, Q, R) vs. photo-induced hydride transfer through the hydrogenated $\mathrm{PPy}$ intermediates (Scheme 3; A, B, C and D). 


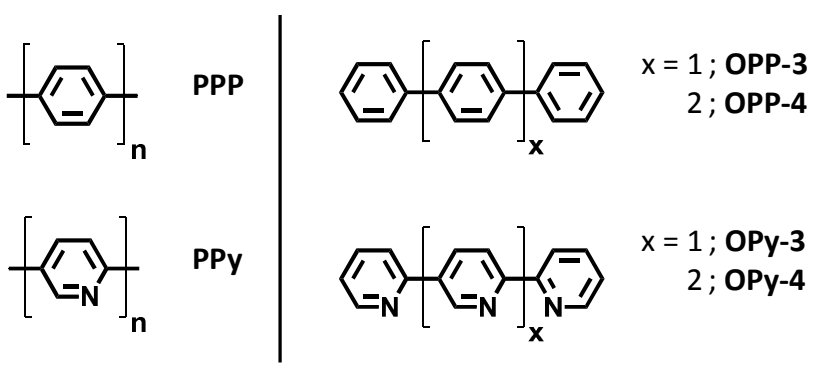

Figure 2: Structures of linear polymers: poly-p-phenylene (PPP), polypyridine-2,5-diyl (PPy) and oligomers used for photocatalysis. ${ }^{64,67,69}$

An interesting question is whether there is a minimum polymer length for which photocatalytic activity is observed. This question was addressed by Matsuoka et al. who compared a series of linear oligomeric $p$-phenylene chains OPP- $n(n=2-6)^{70}$ with each other and with their pyridine analogues (OPy-3 and OPy-4; Figure 2). ${ }^{69}$ They found that three $p$-phenylene (OPP-3) units were necessary for photoinduced charge-separation and, hence, hydrogen evolution to occur; the hydrogen evolution efficiency increased with increasing chain length. Interestingly, the efficiency also scaled with the solubility of the oligomeric model catalysts, giving rise to more efficient hydrogen evolution in the more soluble systems in which homogeneous catalysis may prevail over heterogeneous contributions, albeit at the expense of lower longterm stability. OPP-3 was also shown to photocatalyze the photoreduction of $\mathrm{CO}_{2}$ to formic acid and $\mathrm{CO}$ in the presence of triethylamine as a sacrificial electron donor. ${ }^{71}$ Use of electron mediators such as Cobalt(III) complexes of cyclam $(1,4,8,11$-tetraazacyclotetradecane or related tetraazamacrocycles) facilitates electron transfer from the radical anion of OPP-3 to $\mathrm{CO}_{2}$. Mechanistic and kinetic studies suggest the formation of intermediate $\mathrm{Co}-\mathrm{CO}_{2}$ adducts that assist the electron transfer and improve the overall efficiency of the photoreduction. ${ }^{72,73}$

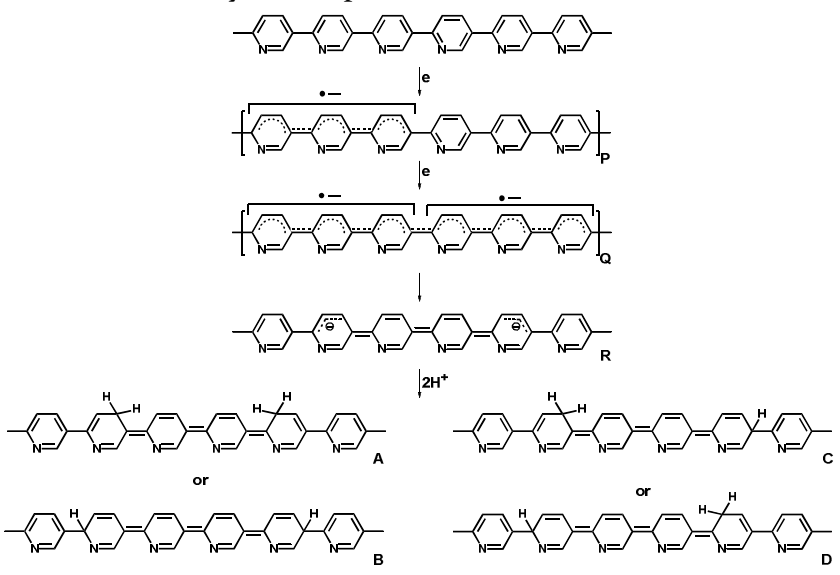

Scheme 3: Proposed mechanism of PPy/OPy-catalyzed photoreductions, which is also invoked to operate in PPP/OPP-type systems. Adapted from reference 68 with permission from The Royal Society of Chemistry.
The oligomeric systems OPy- $n(n=3$ or 4 ; Figure 2$)$ show similar quantum yields at $\lambda=313 \mathrm{~nm}$, which are however superior by at least one order of magnitude to those of their phenyl counterparts OPP- $n \cdot{ }^{69}$ Investigations using $\gamma$-radiolysis, pulse radiolysis and laser flash photolysis revealed that, like for the OPP- $n$ systems, the primary photocatalytic processes in these oligomers involve reductive quenching of the photoexcited singlet state by the sacrificial electron donor triethylamine, giving rise to the anion radical $\mathrm{OPy}-n^{\bullet}$ and the $\mathrm{TEA}^{\bullet+}$ radical cation, followed by noble metal mediated electron transfer from the anion radical to the protons, thereby evolving hydrogen gas (Scheme 4). Photoreduced $\mathrm{RuCl}_{3}$ acts as an electron relay, which is crucial for efficient charge separation and transfer to occur. The protonation of the anion radicals occurs in competition with electron transfer, thus leading to photodegradation of the oligomers and loss of photocatalytic activity. The radical cation $\left(\mathrm{TEA}^{\bullet+}\right)$ further hydrolyzes to give diethylamine and acetaldehyde (Scheme 4).

$$
\begin{aligned}
& \mathrm{OPy}-n+h v \longrightarrow{ }^{1} \mathrm{OPy}-n \text { * } \\
& { }^{1} \mathrm{OPy}-n^{*} \longrightarrow{ }^{3} \mathrm{OPy}-n^{*} \\
& { }^{1} \mathrm{OPy}-n^{*}+\mathrm{Et}_{3} \mathrm{~N} \longrightarrow \mathrm{OPy}-n^{-} \\
& { }^{3} \mathrm{OPy}-n^{*}+\mathrm{Et}_{3} \mathrm{~N} \longrightarrow \mathrm{OPy}-n^{-} \\
& \text {OPy- } n^{--} \longrightarrow \text { OPy }-n+\mathrm{e}^{-} \\
& 3 \mathrm{e}^{-}+\mathrm{RuCl}_{3} \longrightarrow \mathrm{Ru}^{0} \\
& \mathbf{e}^{-}+\mathbf{H}^{+} \stackrel{\mathbf{R u}^{0}}{\longrightarrow} \quad 1 / 2 \mathbf{H}_{2} \\
& \mathrm{OPy}^{*} n^{*}+\mathrm{H}^{+} \longrightarrow \mathrm{OPy}-n-\mathrm{H}^{\cdot} \\
& \mathrm{Et}_{2} \mathrm{~N}^{-} \mathrm{CH}_{2} \mathrm{CH}_{3} \stackrel{2 \mathrm{~h}_{\mathrm{vB}}-\mathrm{H}^{+}}{\longrightarrow} \mathrm{Et}_{2} \mathrm{~N}^{+} \mathrm{CHCH}_{3} \stackrel{\mathrm{OH}^{-}}{\longrightarrow} \mathrm{Et}_{2} \mathrm{NH}+\mathrm{CH}_{3} \mathrm{CHO}
\end{aligned}
$$

Scheme 4: Hydrogen evolution mechanism using pyridine oligomers as photocatalysts. Adapted with permissions from references 69 and 66 from The Royal Society of Chemistry and the American Chemical Society.

Nearly two decades after Yanagida's work, the interest in organic polymeric semiconductors for photocatalytic hydrogen evolution is back. ${ }^{74},{ }^{75}$ Using low molecular weight conjugated phenylene oligomers with up to six $p$ substituted phenyl rings, Cooper and co-workers noted an increase in photocatalytic hydrogen evolution with increasing oligomer size..$^{75}$ As a means of increasing conjugation across the polymer chain, a bridging group between the phenyls in the linear oligomers was introduced. The lowering of the torsional angle leads to greater charge delocalization. The result of decreasing the optical gap can be seen in an increased hydrogen evolution rate when compared with the non-planar polyphenyl oligomers. The authors propose that the increased efficiency of the planar analogues primarily stems from longer charge carrier lifetimes, induced by the increased conjugation length, 
thus pointing out important design principles affecting the charge carrier dynamics in polymer photocatalysis.

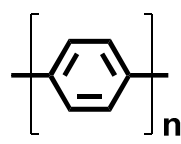

\section{P1K: by Kumada coupling P1S: by Suzuki coupling}

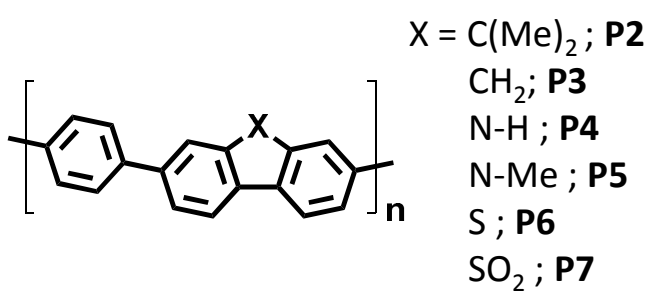

Figure 3: Structures of poly- $p$-phenylenes synthesized by Kumada $\left(\mathrm{P}_{1} \mathrm{~K}\right)$ and Suzuki coupling $(\mathrm{P} 1 \mathrm{~S})$ and planarized polymers with carbon or heteroatom substitution $\left(\mathrm{P}_{2}-\mathrm{P}_{7}\right)$. Adapted from reference 75 under a Creative Commons Attribution License.

A further extension in the conjugation length by polymerization led to a series of linear polymers (Figure 3) that include poly-p-phenylenes synthesized by Kumada $(\mathrm{P} 1 \mathrm{~K})$ or Suzuki coupling $(\mathrm{P} 1 \mathrm{~S}) \cdot{ }^{75}$ Analogous conjugated co-polymers with phenyl 1,4-diboronic acid and planarized units such as fluorene $\left(\mathrm{P}_{2}, \mathrm{P}_{3}\right)$, and with heteroatom substitution - carbazole $\left(\mathrm{P}_{4}, \mathrm{P}_{5}\right)$, dibenzo[b,d]thiophene (P6) and dibenzo[b,d]thiophene sulfone $\left(\mathrm{P}_{7}\right)$ - were also prepared. The photochemical hydrogen evolution shows an increasing trend when compared with the other linear analogues ( $\mathrm{P}_{1} \mathrm{~K} ; 2.0 \mu \mathrm{mol} \mathrm{h}^{-1}$ and $\mathrm{P}_{1} \mathrm{~S} ; 3.9 \mu \mathrm{mol} \mathrm{h}^{-1}$ ) upon planarization and heteroatom substitution from $\mathrm{CMe}_{2}$ $\left(\mathrm{P}_{2} ; 8.3 \mu \mathrm{mol} \mathrm{h}^{-1}\right)$ to $\mathrm{N}-\mathrm{H} \quad\left(\mathrm{P}_{4} ; 7.8 \mu \mathrm{mol} \mathrm{h}^{-1}\right)$, S (P6; $\left.26.6 \mu \mathrm{mol} \mathrm{h}^{-1}\right)$ and $\mathrm{SO}_{2}\left(\mathrm{P}_{7} ; 92.2 \mu \mathrm{mol} \mathrm{h}^{-1}\right)$ in methanolic triethylamine under $>420 \mathrm{~nm}$ irradiation. The optical bandgap of the polymers shows a narrow distribution from 2.72 to $2.86 \mathrm{eV}$ thus leading to very similar light harvesting abilities. Furthermore, DFT calculations do not indicate significant differences in the thermodynamic driving force for proton reduction in these polymers. Thus, a combination of longer charge carrier lifetime, higher charge carrier mobility arising from planarity, and increasing rigidity of the polymer network was elaborated as a plausible explanation for the observed trend.

\subsection{All-polymer nanocomposites}

Heterojunction design, i.e. casting two types of polymers with complementary bandgap into nanoscale bicontinuous donor-acceptor architectures, can be a suitable method for facilitating the separation and extraction of photogenerated charge carriers. Coupling low bandgap polymers with high charge carrier mobility as photosensitizers with organic polymers having the desired bandgap and band level alignment for photocatalytic hydrogen evolution can lead to higher photocatalytic activity. Heterojunction designs have successfully been used in OPV for photocurrent generation and are expected to improve the separation of photogenerated electron-hole pairs following exciton formation. Poly(3-hexylthiophene) $\left(\mathrm{P}_{3} \mathrm{HT}\right)$ - a semiconductor with an optical gap of 1.9-2.1 eV - when mixed with $\mathrm{g}-\mathrm{C}_{3} \mathrm{~N}_{4}$ results in a 30o-fold improvement in hydrogen evolution when compared with pristine g- $\mathrm{C}_{3} \mathrm{~N}_{4}$ using sulfide/sulfite as the sacrificial electron donors with Pt as the co-catalyst. ${ }^{76}$ Using as little as $3 \mathrm{wt} \%$ of $\mathrm{P}_{3} \mathrm{HT}$ (with $\mathrm{g}-\mathrm{C}_{3} \mathrm{~N}_{4}$ ) leads to a high $\mathrm{H}_{2}$ evolution rate of $560 \mu \mathrm{mol} \mathrm{h}^{-1}$. Photoluminescence (PL) quenching studies show a decrease in intensity of $\mathrm{g}-\mathrm{C}_{3} \mathrm{~N}_{4}$ emission upon addition of $\mathrm{P}_{3} \mathrm{HT}$. Nearly $60 \%$ PL intensity of $\mathrm{g}-\mathrm{C}_{3} \mathrm{~N}_{4}$ was quenched with the addition of mere $1 \mathrm{wt} \% \mathrm{P}_{3} \mathrm{HT}$, thus suggesting efficient charge transfer between the two components (Figure 4a).

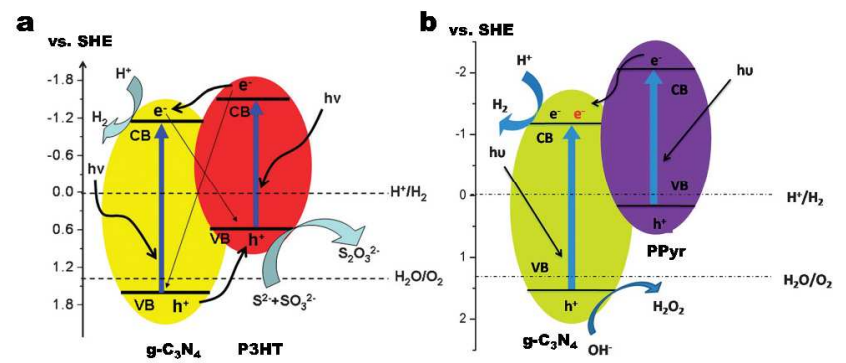

Figure 4: Proposed mechanism for photocatalytic hydrogen evolution using a g- $\mathrm{C}_{3} \mathrm{~N}_{4}$ nanocomposite with conductive polymers. a) With P3HT in the presence of sacrificial electron donor and $b$ ) with PPyr without sacrificial agent. Reproduced from reference 76 and 77 with permission from The Royal Society of Chemistry.

Another conductive organic polymer employed to form a bulk heterojunction with $\mathrm{g}-\mathrm{C}_{3} \mathrm{~N}_{4}$ is polypyrrole (PPyr). Using $1.5 \mathrm{wt} \%$ of PPyr in the nanocomposite, a 50 -fold increase in hydrogen evolution was observed in the presence of $\mathrm{Pt}$ co-catalyst without any sacrificial electron donor. ${ }^{77}$ The authors argue that the use of conductive polymers increases the surface electronic conductivity and facilitates the transport of the photogenerated electrons and holes. As the valence band (VB) and conduction band $(\mathrm{CB})$ of the conducting polymers are more negative than the $\mathrm{VB}$ and $\mathrm{CB}$ of $\mathrm{g}-\mathrm{C}_{3} \mathrm{~N}_{4}$, the conducting polymer also acts as a photosensitizer, transferring electrons in the photoexcited polymer to $\mathrm{g}-\mathrm{C}_{3} \mathrm{~N}_{4}$ and thus more electrons are available for proton reduction. The holes in turn are either quenched by $\mathrm{P}_{3} \mathrm{HT}$ acting as sacrificial electron donor or oxidize hydroxide ions, yielding $\mathrm{H}_{2} \mathrm{O}_{2}$ when used in pure water (Figure $4 \mathrm{~b}$ ).

\subsection{Conjugated Porous Polymers}

Organic two-dimensional (2D) polymers exhibit extended $\pi$-conjugation combined with structural and textural micro- or mesoporosity; the systems discussed in this section are invariably amorphous, i.e. do not possess long-range order. $2 \mathrm{D}$ porous polymers have been extensively explored in areas such as gas adsorption, heterogeneous catalysis, and sensing. ${ }^{78}$ As photocatalysts for solar fuel generation, however, these polymers have hardly been investigated to date. In fact, only a handful of systems besides the ubiquitous carbon nitrides have been 
reported. Müllen and coworkers prepared a series of poly(azomethine) networks ( $\mathrm{AB}_{1}-\mathrm{AB}_{4}$; Figure 5) using 1,3,5-tris(4-aminophenyl)benzene (A) with bifunctional aromatic aldehydes containing benzene $\left(\mathrm{B}_{2}\right)$, naphthalene (B3) and anthracene ( $\mathrm{B}_{4}$ and $\mathrm{B}_{5}$ ) cores. ${ }^{79}$ Using DFT calculations the authors show that the positions of the $\mathrm{HO}$ MOs largely lie on the aromatic chromophore containing the aldehydic groups (Figure $5 \mathrm{c}$ and $\mathrm{c}$ ). This in turn influences the light harvesting properties of the polymers as seen in their optical bandgap which ranges from 2.38 to $1.96 \mathrm{eV}$. Using triethanolamine as sacrificial electron donor and Pt as co-catalyst, the amount of photocatalytically produced hydrogen was found to be 1.5, 6.7, 6.2 and $0.7 \mu \mathrm{mol} \mathrm{h}^{-1}$ for $\mathrm{AB}_{1}, \mathrm{AB}_{2}, \mathrm{AB}_{3}$ and $\mathrm{AB}_{4}$, respectively. The lower photocatalytic activity of $\mathrm{AB}_{4}$ in comparison to $\mathrm{AB}_{3}$ in spite of similar optical bandgaps presumably arises from poorer charge transport in the former due to the higher torsional angle of the chromophore $\left(\mathrm{B}_{4}\right)$ in the polymer. These results clearly point to the fact that the optical gap is an important but not the sole factor in determining photocatalytic activity.

a
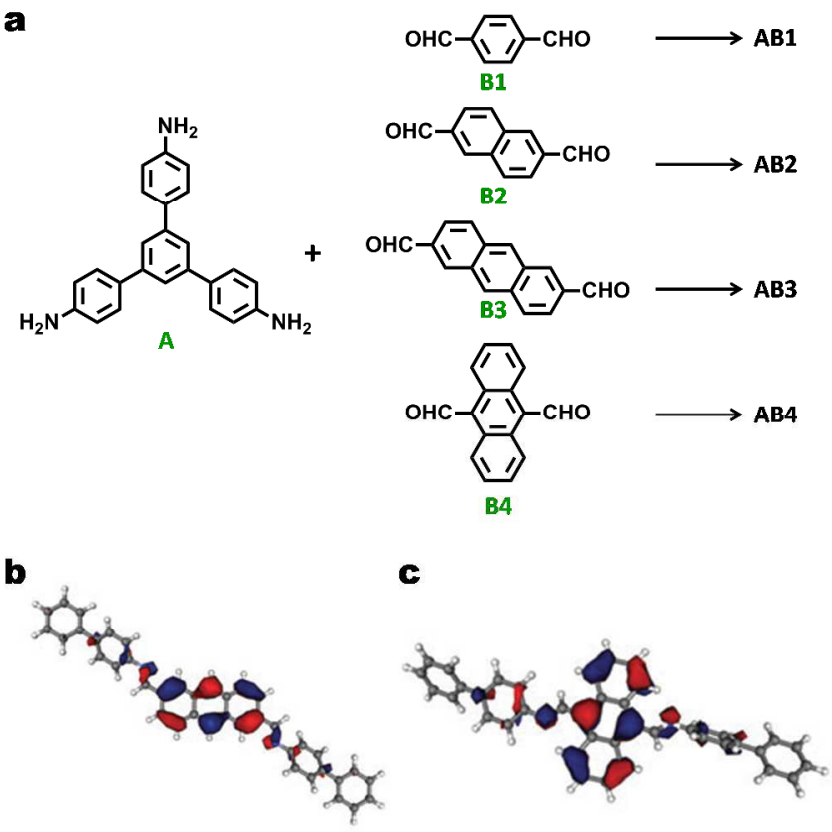

Figure 5: a) Building blocks of $2 \mathrm{D}$ polymers $\left(\mathrm{AB}_{1}-\mathrm{AB}_{4}\right)$ synthesized from 1,3,5-tris(4-aminophenyl) benzene (A) and a series of bifunctional aromatic aldehydes - terephthalaldehyde ( $\left.\mathrm{B}_{1}\right)$, naphthalene-2,6-dicarbaldehyde ( $\left.\mathrm{B} 2\right)$, anthracene2,6-di-carbaldehyde (B3) and anthracene-9,10dicarbaldehyde (B4). b \& c) Graphical HOMO representation of the model segments from $\mathrm{AB}_{3}$ (b) and $\mathrm{AB}_{4}$ (c) obtained by geometry-optimized DFT calculations (B3LYP, 6-311G**). Adapted from reference 79 with permission from The Royal Society of Chemistry.

Using the statistical copolymerization approach, the Cooper group reported a series of conjugated microporous polymers (CMPs) where the optical gap was tuned by changing the proportions of phenyl and pyrene building blocks. ${ }^{74}$ The chromophores were introduced into the polymers by Suzuki-Miyaura coupling using 1,4benzene diboronic acid (A) and 1,2,4,5tetrabromobenzene (B) as phenyl precursor, while the 1,3,6,8-tetraboronic pinacol esters of pyrene (C) and 1,3,6,8-tetrabromopyrene (D) were the sources for the pyrene chromophore. Under visible light (> $420 \mathrm{~nm}$ ) irradiation, all CMPs showed steady hydrogen production using diethyl amine as the sacrificial electron donor without any added noble metal co-catalyst (Figure 6). As a direct consequence of bandgap engineering, the polymers show an increasing hydrogen evolution rate with decreasing optical gap from $2.95 \mathrm{eV}$ for CMP1 $\left(1 \mu \mathrm{mol} \mathrm{h}^{-1}\right)$ to $2.33 \mathrm{eV}$ for CMP1o $\left(17.4 \mu \mathrm{mol} \mathrm{h}^{-1}\right)$. A further decrease in bandgap, however, led to a decrease in photocatalytic activity that was attributed to either an increased nonradiative electron-hole recombination or an increase in electron transfer barrier between the polymers and protons in the pyrene-rich CMPs. $2 \mathrm{D}$ conjugated polymers thus bring together essential elements of linear polymers in terms of conjugation and easy synthesis. Additionally, they offer the added benefits of extended $\pi$-overlap across and, in some cases, perpendicular to the layers, porosity and increased robustness of the chromophors by locking them in place through the network formation.
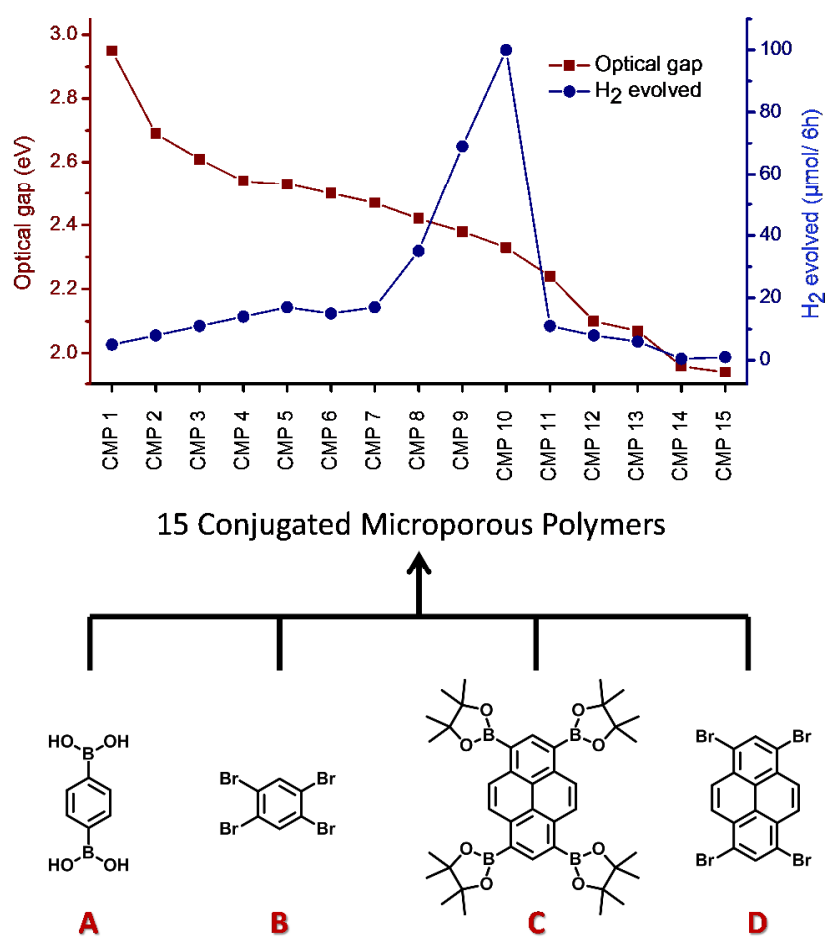

Figure 6: Conjugated microporous polymers (CMP 1 to 15 ) synthesized by statistical co-polymerization of the four monomers A, B, C and D. The CMPs show a steady decrease in optical bandgap (red squares) as a function of increasing pyrene content. Upon irradiation with visible light for 6 hours using diethylamine as sacrificial electron donor, the 
copolymers show sustained photocatalytic hydrogen evolution (blue circles) with a maximum observed rate at a bandgap of $2.3 \mathrm{eV}$. Adapted from reference 20 .

\subsection{Covalent Triazine Frameworks (CTFs)}

$\mathrm{CTFs}^{80-85}$ represent a bridge between the carbon nitride class of materials and conjugated organic polymers, combining the thermally stable and robust triazine motif from PTI-type carbon nitrides with variable, rigid aromatic linkers to extend the $\pi$-conjugation and functionality as found in conjugated polymers. Unlike carbon nitrides though, CTFs are inherently micro- and mesoporous $2 \mathrm{D}$ polymers and, as such, are more akin to the broader class of $\pi$-conjugated porous polymers and covalent organic frameworks, depending on their structural order. CTFs are prepared under ionothermal conditions by the trimerization of aromatic nitriles using a Lewis or Brønsted acid catalyst, typically either $\mathrm{ZnCl}_{2}$ or trifluoromethanesulfonic acid. Depending on the linker and synthesis conditions, the porous frameworks typically have high nitrogen contents and multimodal pore size distributions with a high fraction of ultramicropores and BET surface areas up to $3000 \mathrm{~m}^{2} \mathrm{~g}^{-1}$, which render them also interesting candidates for carbon capture and storage with high $\mathrm{CO}_{2}$ over $\mathrm{N}_{2}$ selectivity. ${ }^{81,82,86}$ Modelling of the optical ${ }^{87}$ and electronic structures ${ }^{88}$ has recently shown that some CTFs, namely CTF-o and CTF-1, have frontier orbitals that straddle the water reduction and oxidation potentials while having energy transitions sufficiently narrow for visible light excitation (Figure 7). Combined with their porous morphology, their optoelectronic properties make them promising photocatalysts for water splitting. Although photocatalytic hydrogen and oxygen evolution in sacrificial systems have been claimed for $\mathrm{CTF}_{-1}{ }^{89}$, our investigation indicates that only phenyl triazine oligomers (PTOs) are substantially active as hydrogen evolution catalysts. The extended polymer CTF-1, synthesized following the original conditions $\left(400{ }^{\circ} \mathrm{C}\right.$ using $\mathrm{ZnCl}_{2}$ ), has only minute hydrogen evolution activity, which may be attributed to extensive carbonization of the material. ${ }^{82}$ Reducing the synthesis temperature (to $300{ }^{\circ} \mathrm{C}$ ) and the $\mathrm{ZnCl}_{2}$ to precursor ratio yields incompletely condensed yet active photocatalysts for hydrogen evolution, with activities exceeding those of the benchmark carbon nitrides PTI and melon. ${ }^{90}$ Such triazine-based oligomeric chains and rings with residual nitrile terminations show increased crystallinity and hydrophilicity, which improves their dispersion in aqueous solution. In addition, the nitrile function may provide anchoring sites to the Pt cocatalyst and facilitate interfacial charge transfer of the photoelectrons to the substrate..$^{91}$

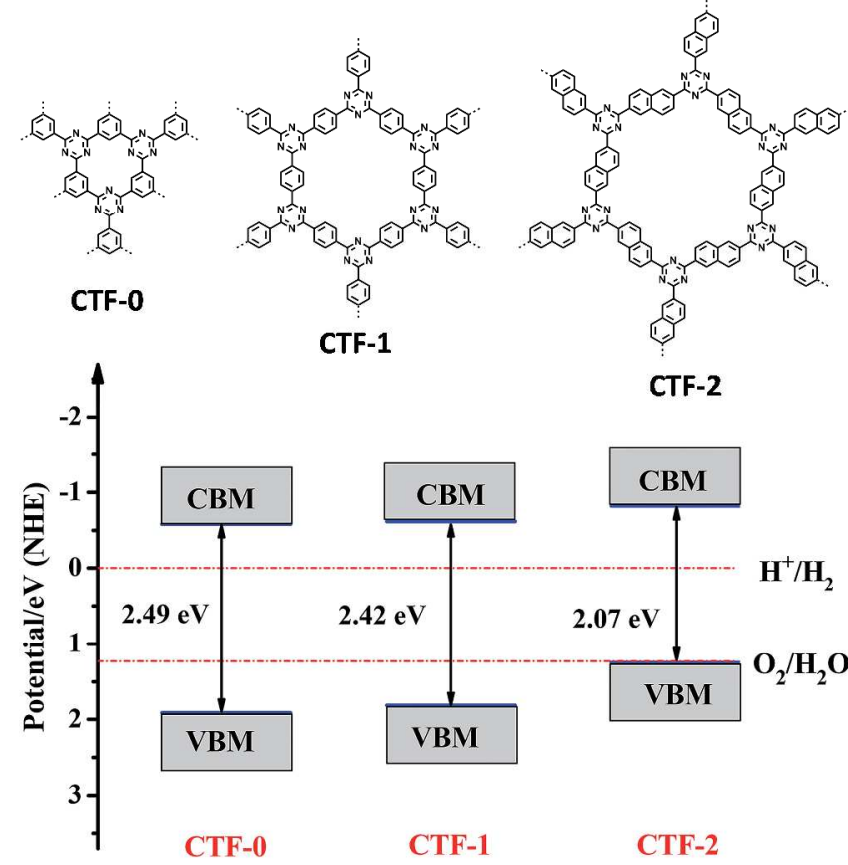

Figure 7: Structural motifs of covalent triazine frameworks CTF-o, CTF-1, and CTF-2 (above), and their calculated electronic structures (below). Adapted from reference 92 with permission from The Royal Society of Chemistry.

Hence, while the optoelectronic properties dictate whether the thermodynamic requirements for photocatalytic hydrogen evolution are satisfied, the kinetics of charge transport and charge transfer at the polymersolution interface are influenced by the material's interactions with the substrates and/or co-catalyst(s), which are determined by the moieties present at the polymer terminations. The role of such "functional defects" thus highlights the necessity of considering kinetics in addition to the underlying thermodynamics in the synthetic design of photocatalysts based on organic polymers.

\subsection{Covalent Organic Frameworks (COFs)}

The special charm of COFs lies in their inherent crystallinity which the aforementioned $2 \mathrm{D}$ organic polymers conspicuously lack. COFs are $2 \mathrm{D}$ or $3 \mathrm{D}$ frameworks which are formed from di- or multitopic rigid aromatic linkers in solvothermal reactions. The reversibility in bond formation between the building blocks, using dynamic covalent chemistry protocols, dictates the long range order in these materials. Hence, COFs are well defined materials on the local level and periodically - that feature high surface areas and porosity in the micro- and mesopore range. ${ }^{93-95}$ However, as condensation reactions are typically employed to realize reversibility in bond formation, this comes at the expense of network stability, specifically with respect to hydrolysis. For this reason, a large number of COFs are primarily investigated for gas storage and separation or their optoelectronic properties. ${ }^{96,97}$

With increasing complexity of the building blocks used in COF synthesis and the development of suitable linking 
schemes came the era of stable COFs that helped diversify the range of applications for this class of crystalline porous polymers. Important landmarks in this regard include hydrazone $\mathrm{e}^{98}$ and azine ${ }^{99}$ linkages as well as the 'locking strategy' devised by the Banerjee group ${ }^{100,}{ }^{101}$ for providing stability to the imine linkage through a ketoenol tautomerism. More importantly, the introduction of electro ${ }^{102}$ and photoactive organic chromophores capable of light harvesting, photoactivation and photoconduction ${ }^{26,97,103-106}$ led to the recognition of COFs beyond classical porous materials and became an important stepping stone for the development of COFs for solar fuel production by our group.

Condensing a porphyrin skeleton (copper(II) 5,10,15,20tetrakis(4-aminophenyl)porphyrin) with squaric acid, Jiang and coworkers synthesized a stable COF (CuP-SQ) with extended $\pi$-conjugation within and perpendicular to the COF plane, resulting in a small bandgap of $1.7 \mathrm{eV} .^{107}$ The COF shows promising photocatalytic activity by triggering the activation of molecular oxygen to form reactive singlet oxygen. The authors conclude that the $\pi$ conjugated COF architecture facilitates charge transfer, thus demonstrating the possibility to use the inherent photoactivity of the COF building blocks to participate in chemical transformations.

Combining the salient features of COFs such as crystallinity, porosity and stability with the ability of extended visible light harvesting led to the genesis of COFs capable of photocatalytic hydrogen evolution. Using 1,3,5-tris-(4formyl-phenyl)triazine (TFPT) and 2,5-diethoxyterephthalohydrazide (DETH) building blocks, we developed a hydrolytically stable hydrazone-based COF possessing a bandgap of $2.8 \mathrm{eV} .^{108}$ Using ascorbic acid as sacrificial electron donor and Pt as co-catalyst, TFPT-COF showed sustained hydrogen evolution for up to 3 days under visible light irradiation for the first time. Apparent quantum efficiencies of around $2 \%$ put this COF system on par with prototypical carbon nitride photocatalysts, with large scope for optimization still available, both at the building block and the framework level. Although long term photocatalysis led to a loss in long range order (but not activity) of the COF, likely due to exfoliation, ${ }^{109}$ crystallinity was re-installed after photocatalysis by subjecting the COF to the initial synthesis conditions.

Efficient light capture and high porosity of COFs also provide an ideal platform for anchoring photocatalytically active nanoparticles to the COF. Here, the latter primarily acts as a sensitizer and provides a large surface area scaffold which can increase the catalytic activity of the nanoparticles. Combining CdS nanoparticles with a COF synthesized from 1,3,5-triformylphloroglucinol with 2,5dimethyl-p-phenylenediamine, Banerjee and co-workers developed a hybrid system that shows significantly improved photocatalytic hydrogen evolution using lactic acid as sacrificial electron donor and Pt as co-catalyst. ${ }^{110}$ The photocatalytic hydrogen production increased about 30-fold to $3678 \mu \mathrm{mol} \mathrm{h}^{-1} \mathrm{~g}^{-1}$ using a CdS-COF (90:10) hybrid compared to a rate of $128 \mu \mathrm{mol} \mathrm{h}^{-1} \mathrm{~g}^{-1}$ with CdS alone.

As with linear polymers, the key idea for exploring COFs as photocatalysts is to avail the richness of organic chemistry in providing readily tunable building blocks. We synthesized a series of $2 \mathrm{D}$ azine-linked COFs using a triphenylarene platform that was tuned for photocatalytic water reduction through molecular engineering (Figure 8). ${ }^{111}$ The building blocks included hydrazine and triphenylarylaldehydes differing in the number of nitrogen atoms (from zero to three) in the central aryl ring. This subtle modification on the local molecular level translates directly into varying degrees of planarity of the building blocks which in turn leads to gradual changes in the overall crystallinity, morphology and optoelectronic properties of the resulting COFs, clearly in consonance with the nitrogen content. Although all four COFs showed similar absorption profiles with an optical bandgap between 2.6 and $2.7 \mathrm{eV}$, the increase in nitrogen content and hence the planarity of the building blocks led to a gradual increase in porosity and crystallinity from $\mathrm{N}_{0}-\mathrm{COF}$ to $\mathrm{N}_{3}-$ COF.

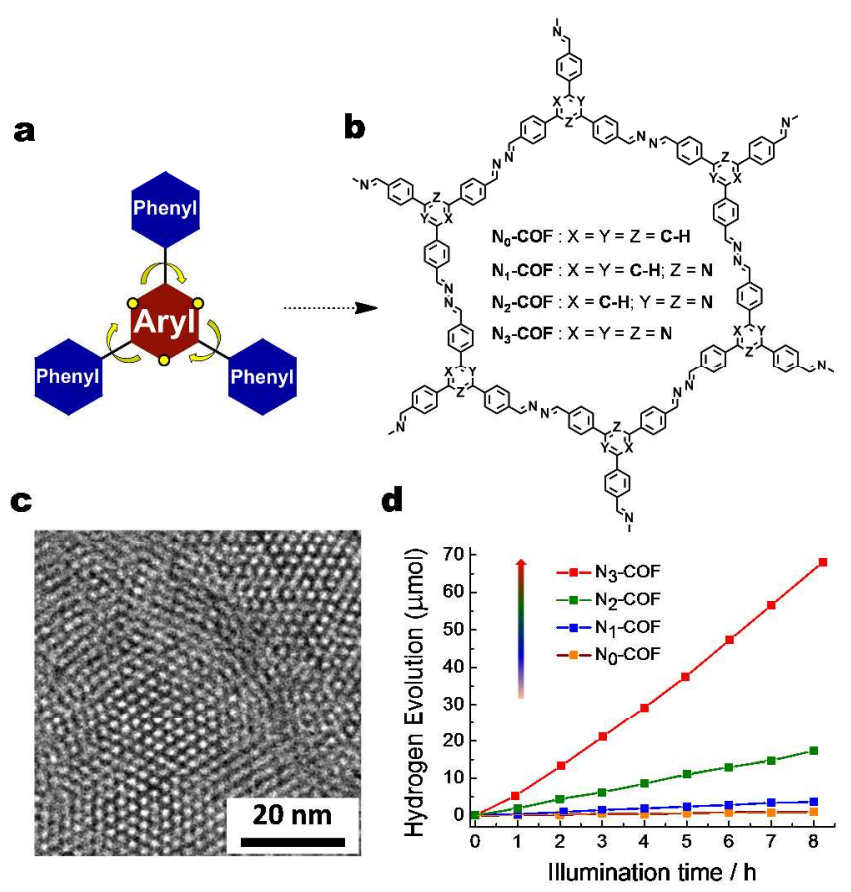

Figure 8: Modulating covalent organic frameworks for photocatalytic hydrogen evolution. a) A platform for synthesizing COFs with gradually varying nitrogen content. b) Structure of the $\mathrm{N}_{\mathrm{x}}$-COFs. c) TEM image of $\mathrm{N}_{3}$-COF. d) Increasing photocatalytic hydrogen evolution activity as a consequence of molecular engineering. Adapted from reference 111 under a Creative Commons CC-BY license.

Interestingly, with each isolobal substitution of $\mathrm{C}-\mathrm{H}$ by $\mathrm{N}$ in the central aryl ring of the COF platform, a fourfold increase in hydrogen evolution was observed under visible light irradiation. The average amount of hydrogen produced by the series $\mathrm{N}_{0}, \mathrm{~N}_{1}, \mathrm{~N}_{2}$ and $\mathrm{N}_{3}$-COF was found 
to be $0.1,0.4,2.2$ and $8.5 \mu \mathrm{mol} \mathrm{h}^{-1}$, respectively. Analysis of the COFs after photocatalysis did not indicate any noticeable change in connectivity or long range order.

Table 1: Summary of the photocatalytic activities and quantum efficiencies (where given) for hydrogen production reported for organic polymeric semiconductors. Detailed experimental conditions are given below.

\begin{tabular}{|c|c|c|c|c|c|c|c|}
\hline \multirow{2}{*}{ Photocatalyst } & \multirow{2}{*}{$\begin{array}{l}\text { Optical gap } \\
(\mathrm{eV})\end{array}$} & \multirow{2}{*}{$\begin{array}{l}\text { BET Surface } \\
\text { Area }\left(\mathrm{m}^{2} \mathrm{~g}^{-1}\right)\end{array}$} & \multicolumn{2}{|c|}{ Activity $\left(\mu \mathrm{mol} \mathrm{h}^{-1}\right)$} & \multirow{2}{*}{ QE (\%) } & \multirow{2}{*}{ Conditions } & \multirow{2}{*}{ Ref } \\
\hline & & & visible light & full spectrum & & & \\
\hline PPP & 2.9 & 39.1 & 0.03 & 2.1 & $<0.04$ & A & 64 \\
\hline PPP-11 & 2.9 & 44 & 0.1 & 0.6 & & B & 66 \\
\hline PPP-11-Ru & 2.9 & & 0.3 & $5 \cdot 5$ & 0.015 & B & 66 \\
\hline PPy (with Ru) & 2.4 & & 2.5 & & 0.21 & C & 68 \\
\hline $\mathrm{P} 1 \mathrm{~K}$ & 2.79 & - & 2.0 & 10.3 & 0.13 & $\mathrm{D}$ & 75 \\
\hline PiS & 2.78 & - & 3.9 & 14.3 & & $\mathrm{D}$ & 75 \\
\hline $\mathrm{P}_{2}$ & 2.79 & - & 8.3 & 43.6 & & $\mathrm{D}$ & 75 \\
\hline $\mathrm{P}_{3}$ & 2.86 & - & 0.1 & 49.2 & & $\mathrm{D}$ & 75 \\
\hline $\mathrm{P}_{4}$ & 2.72 & - & 7.8 & 35.1 & & $\mathrm{D}$ & 75 \\
\hline $\mathrm{P}_{5}$ & 2.78 & - & 2.2 & $27 \cdot 3$ & & $\mathrm{D}$ & 75 \\
\hline P6 & 2.77 & - & 26.6 & 102.4 & 1.10 & $\mathrm{D}$ & 75 \\
\hline $\mathrm{P}_{7}$ & 2.70 & - & 92.0 & 145.0 & 2.25 & $\mathrm{D}$ & 75 \\
\hline $3 \mathrm{wt} \% \mathrm{P}_{3} \mathrm{HT}-\mathrm{g}-\mathrm{C}_{3} \mathrm{~N}_{4}$ & 1.89 & & 560 & & 2.9 & E & 76 \\
\hline $1.5 \mathrm{wt} \%$ PPPyr-g- $\mathrm{C}_{3} \mathrm{~N}_{4}$ & 2.75 & & & 15.4 & & $\mathrm{~F}$ & 77 \\
\hline $\mathrm{AB} 1$ & 2.38 & & & 1.5 & & G & 79 \\
\hline $\mathrm{AB}_{2}$ & 2.46 & & & 6.7 & & G & 79 \\
\hline $\mathrm{AB}_{3}$ & 2.10 & & & 6.2 & & G & 79 \\
\hline $\mathrm{AB}_{4}$ & 1.96 & & & 0.7 & & G & 79 \\
\hline CMP1 & 2.95 & 597 & $1.0 \pm 0.1$ & & $13 \cdot 4$ & $\mathrm{H}$ & 74 \\
\hline $\mathrm{CMP}_{2}$ & 2.69 & 682 & $1.4 \pm 0.1$ & & $7 \cdot 9$ & $\mathrm{H}$ & 74 \\
\hline $\mathrm{CMP}_{3}$ & 2.61 & 710 & $1.8 \pm 0.2$ & & 5.4 & $\mathrm{H}$ & 74 \\
\hline $\mathrm{CMP}_{4}$ & 2.54 & 684 & $2.4 \pm 0.1$ & & $5 \cdot 3$ & $\mathrm{H}$ & 74 \\
\hline $\mathrm{CMP}_{5}$ & 2.53 & 734 & $3.0 \pm 0.2$ & & $9 \cdot 3$ & $\mathrm{H}$ & 74 \\
\hline CMP6 & 2.5 & 726 & $2.6 \pm 0.2$ & & 5.8 & $\mathrm{H}$ & 74 \\
\hline $\mathrm{CMP}_{7}$ & 2.47 & 839 & $2.9 \pm 0.2$ & & $5 \cdot 7$ & $\mathrm{H}$ & 74 \\
\hline CMP8 & 2.42 & 1056 & $6.0 \pm 0.6$ & & $5 \cdot 3$ & $\mathrm{H}$ & 74 \\
\hline $\mathrm{CMP}_{9}$ & 2.38 & 762 & $10.9 \pm 0.1$ & & 3.8 & $\mathrm{H}$ & 74 \\
\hline CMPıo & 2.33 & 995 & $17.4 \pm 0.9$ & & 4.2 & $\mathrm{H}$ & 74 \\
\hline CMPı1 & 2.24 & 770 & $2.0 \pm 0.2$ & & 0.5 & $\mathrm{H}$ & 74 \\
\hline $\mathrm{CMP}_{12}$ & 2.1 & 987 & $1.4 \pm 0.2$ & & 0.6 & $\mathrm{H}$ & 74 \\
\hline $\mathrm{CMP}_{13}$ & 2.07 & 1710 & $1.0 \pm 0.1$ & & 0.4 & $\mathrm{H}$ & 74 \\
\hline $\mathrm{CMP}_{14}$ & 1.96 & 1525 & $<0.1$ & & 0.2 & $\mathrm{H}$ & 74 \\
\hline $\mathrm{CMP}_{15}$ & 1.94 & 1218 & $0.2 \pm<0.1$ & & 0.3 & $\mathrm{H}$ & 74 \\
\hline РTO & 3.2 & 19 & 10.8 & & $5 \cdot 5$ & I & 90 \\
\hline CTF-1 & 2.94 & 19 & 250 & & 2.4 & $\mathrm{~J}$ & 89 \\
\hline TFPT-COF & 2.8 & 1603 & 19.7 & & 2.2 & $\mathrm{~K}$ & 108 \\
\hline CdS - COF (90:10) & & 174 & 110 & & 4.2 & $\mathrm{~L}$ & 110 \\
\hline
\end{tabular}




$\begin{array}{lllllll}\mathrm{N}_{\mathrm{o}}-\mathrm{COF} & 2.67 & 702 & 0.1 & - & \mathrm{M} & 111 \\ \mathrm{~N}_{1}-\mathrm{COF} & 2.68 & 326 & 0.4 & 0.08 & \mathrm{M} & 111 \\ \mathrm{~N}_{2}-\mathrm{COF} & 2.62 & 1046 & 2.2 & 0.19 & \mathrm{M} & 111 \\ \mathrm{~N}_{3}-\mathrm{COF} & 2.65 & 1537 & 8.5 & 0.44 & \mathrm{M} & 111\end{array}$

A: $20 \mathrm{mg}$ polymer in water/diethylamine (1:1) solution, irradiated by $300 \mathrm{~W}$ mercury lamp. Full spectrum (>290 nm). Visible light irradiation at $>400 \mathrm{~nm}$ with $10 \mathrm{mg}$ polymer in water/diethylamine (1:3). Apparent quantum yield.

B: $10 \mathrm{mg}$ polymer in water/MeOH/triethylamine solution with (Ru 1.4\%) co-catalyst, irradiated by $300 \mathrm{~W}$ Xe lamp. Full spectrum (>290 nm). Apparent quantum yield at $405 \mathrm{~nm}$.

C: $10 \mathrm{mg}$ polymer in water/MeOH/triethylamine solution, irradiated by $300 \mathrm{~W}$ halogen lamp fitted with a sodium nitrite solution filter. Visible light $(>400 \mathrm{~nm})$. Apparent quantum yield at $450 \mathrm{~nm}$.

D: $25 \mathrm{mg}$ polymer in water/MeOH/triethylamine solution, irradiated by $300 \mathrm{~W}$ Xe lamp. Visible light (>420 $\mathrm{nm}$ ) and full spectrum (>325 $\mathrm{nm}$ ). Apparent quantum yield at $420 \mathrm{~nm}$.

E. $300 \mathrm{mg}$ polymer with Pt co-catalyst in $0.25 \mathrm{M} \mathrm{Na}_{2} \mathrm{~S}-0.25 \mathrm{M} \mathrm{Na}_{2} \mathrm{SO}_{3}$ solution, irradiated by $300 \mathrm{~W}$ mercury lamp. Visible light (>400 nm). Apparent quantum yield at $420 \mathrm{~nm}$.

F. $100 \mathrm{mg}$ polymer with Pt co-catalyst in water, irradiated by $300 \mathrm{~W}$ Xe lamp using simulated solar light.

G. $100 \mathrm{mg}$ polymer with Pt co-catalyst in 10 vol \% triethanolamine solution irradiated by $300 \mathrm{~W}$ Xe lamp. Full spectrum (>300 nm).

H. $100 \mathrm{mg}$ polymer in $\mathbf{2 0} \%$ diethylamine solution in water, irradiated by $300 \mathrm{~W}$ Xe lamp. Visible light ( $>420$ nm). Absolute quantum yield.

I. $10 \mathrm{mg}$ photocatalyst with Pt co-catalyst (2.5 wt\%) in phosphate buffer and triethanolamine irradiated under simulated sunlight (AM1.5). Apparent quantum yield at $400 \mathrm{~nm}$.

J. 80-100 mg photocatalyst with Pt co-catalyst (1 wt\%) in water (7o mL) and triethanolamine (10 mL) irradiated under visible light (>420 nm). Apparent quantum yield at $400-440 \mathrm{~nm}$.

K. $4 \mathrm{mg}$ polymer in triethanolamine solution irradiated by $300 \mathrm{~W}$ Xe lamp. Visible light $(>420 \mathrm{~nm})$. Pt co-catalyst. Apparent quantum yield at $400 \mathrm{~nm}$.

L. $30 \mathrm{mg}$ polymer in lactic acid solution irradiated by $400 \mathrm{~W}$ Xe lamp. Visible light $(>420 \mathrm{~nm})$. Pt co-catalyst. Apparent quantum yield at 420 $\mathrm{nm}$.

M. 5 mg polymer in PBS buffer and triethanolamine with Pt co-catalyst irradiated by $300 \mathrm{~W}$ Xe lamp. Visible light (>420 nm). Apparent quantum yield at $450 \mathrm{~nm}$.

\section{Outlook}

The advent of organic electronics in the early 1990s, materialized in polymer solar cells, field-effect transistors or organic light-emitting devices, has transformed our daily lives ever since. It is of little surprise that plastic electronics has become a vital branch of material science and one of the most transformative, and steadily growing, technologies over the past thirty years. Given the maturity of this field on the one hand, and the explosive growth of energy materials of just about all stripes on the other, the virtual absence of systematic studies into organic polymeric photocatalysts - besides the ubiquitous carbon nitrides - is stunning. And yet, drawing on the unique achievements and materials kaleidoscope organic electronics has to offer, the field of organic photocatalysis is up for a head start with little inertia to be expected.

One of the arguably most promising polymeric photocatalysts - carbon nitrides - have already been consolidated, testifying not only to the potential of polymers as energy materials, but sensitizing also for their shortcomings. Despite the numerous breakthroughs achieved in carbon nitride photocatalysis in recent years, many aspects of the reaction mechanism and structure-activity relationship in these systems need further exploration. Even though the bulk structures of the prototypical car- bon nitrides melon and PTI have been largely determined, elucidation of their local molecular structures the terminations and "defects" at the solid-liquid interface which are considered to be catalytically relevant $\operatorname{sites}^{29,63}$ - is far more challenging given that bulk averaging characterization techniques are inapplicable. Additionally, these materials lack the chemical reactivity for conventional organic reactions, limiting variability in their structure and the rational insertion of catalytically relevant moieties using synthetic methods. On the other hand, carbon nitrides possess a range of unique features which need to be conserved or emulated in future polymeric photocatalysts. Among these, extremely high thermal and chemical stability as well as appropriate band level positions for water splitting and $\mathrm{CO}_{2}$ reduction are the most important ones to name.

As a first step in this direction, the first photocatalytic platforms based on $\pi$-conjugated organic polymers have been developed, the synthetic flexibility of which enables the rational incorporation of functional groups, whilst providing a rigid and lightweight backbone for heterogeneous photocatalysis. The tunable nature of polymers in turn induces further desirable traits in photocatalysts, including absorptivity in the visible region, extended conjugation for exciton/polaron percolation, the synthetic framework for creating inherently porous, bicontinuous 
donor-acceptor architectures, as well as the facilitation of charge transfer from the catalyst to the sub-strate or cocatalyst. While the synthetic and photophysical tools are largely at hand, research in $\pi$-conjugated polymeric materials for solar fuel generation is still in its infancy. Progress in this field is contingent on identifying the key areas for development along with the major challenges lying ahead. Among these, stability against photodegradation, accessing long-lived photoexcited states and imparting high charge carrier mobilities are lessons to be learnt from organic photovoltaics, organic light-emitting devices and the like. In contrast, a significantly less charted research area involves the catalytic conversion itself, which so far is developed largely disjoint from the polymer backbone and taken care of either by a dedicated molecular or nanoparticulate electrocatalyst. A key question to be addressed in future research will therefore be whether the catalytic conversion can be done either by the polymer itself or by earth-abundant, low cost metal cocatalysts which interact strongly and persistently with the polymer backbone and facilitate charge transfer between the polymer and the substrate.

Along these lines, our recent efforts to identify the active sites responsible for the catalytic conversion at the solid-liquid interface in carbon nitrides have indicated higher activity of oligomers as compared to polymers. On the one hand, this suggests that light harvesting may not be the limiting factor after attaining an optimum length as in linear poly- $p$-phenylenes, where optoelectronic properties tend to converge after 6-7 monomeric units. ${ }^{91}$, ${ }^{112,}{ }^{113}$ On the other hand, the higher activity of oligomers indicates that other factors such as surface terminations may play an important role and therefore need to be considered for the rational design of organic photocatalysts. ${ }^{63}$, ${ }^{90,}{ }^{11}$ Developing an understanding about such catalytically relevant sites intrinsic to the polymer is important to ultimately realize co-catalyst free polymeric photocatalysts. In addition, using well-defined oligomers as model compounds, we believe that useful insights can be drawn regarding the photocatalytic mechanism and structureactivity relationships on the molecular level, including the interaction of the co-catalyst with the light harvesting unit. Moreover, well-defined oligomers furnish better photophysical descriptors such as band positions and bandgaps, and are inherently more accessible to ultrafast optical spectroscopy and highly accurate theoretical modeling which in turn can shine light on the kinetics and thermodynamics of the system.

For example, theoretical calculations by Zwijnenburg and coworkers ${ }^{87,114}$ have offered insights into the thermodynamic descriptors of hydrogen production using organic polymers. Design features such as increasing chain length and heteroatom substitution (especially nitrogen) seem to be critical for decreasing the optical gap, adjusting the energy level positions, increasing exciton lifetimes as well as improving the wettability of the polymers in the solvent mixtures used for photocatalysis.
The principal challenge in this field is to provide a predictive framework that allows for the rational design of polymer photocatalysts through engineering their individual components and orchestrating them to drive the photocatalytic process. Organic materials provide a unique platform for advanced material design by offering virtually infinite possibilities to simultaneously tune the molecular, optical and material properties for solar fuel generation. Where sustainable materials chemistry meets functional design, "soft" polymer photocatalysts mark a promising path forward.

\section{BIOGRAPHY}

Vijay Vyas received B.Sc. honors in Chemistry and M.Sc. in Organic Chemistry from Banaras Hindu University, India and a Ph.D. from Marquette University, Milwaukee in 2012 for his work on through-space charge delocalization studies on polycyclic aromatic hydrocarbons. Since 2012, he is working at the Max Planck Institute for Solid State Research, Stuttgart where his research interests include design, synthesis and application of crystalline (COFs) and amorphous $2 \mathrm{D}$ organic porous polymers for photocatalysis, sensing and drug delivery.

Vincent Wing-hei Lau received his B.Sc (2007) and Ph.D. (2011) from the University of Sydney. He joined the Max Planck Institute for Solid State Research in 2012, working on elucidating the structure-activity relationship of carbon nitride photocatalysts and their rational design. His research interests include material syntheses, heterogeneous electro- and photocatalysis, as well as green chemical processes.

Bettina V. Lotsch studied Chemistry at the LudwigMaximilians-Universität München (LMU) and the University of Oxford and received her $\mathrm{PhD}$ from $\mathrm{LMU} \mathrm{Mu}-$ nich in 2006. In 2007 she joined the group of G. A. Ozin at the University of Toronto as a Feodor-Lynen postdoctoral fellow supported by the Alexander von Humboldt foundation. In 2009, Bettina Lotsch was appointed associate professor at LMU Munich (tenure 2014), and since 2011 she additionally holds a director track position at the Max Planck Institute for Solid State Research in Stuttgart. Her research interests are at the interface between solid-state chemistry, nanochemistry and molecular chemistry and include porous frameworks, 2D materials and nanoscale heterostructures for applications in solar energy conversion, all-solid-state batteries, and chemo-optical sensing. Bettina was named Fellow of the Royal Society of Chemistry in 2014 and is recipient of an ERC Starting grant (2014).

\section{AUTHOR INFORMATION}

\author{
Corresponding Author \\ * E-mail: b.lotsch@fkf.mpg.de, Tel.: +49 711689 1610, Fax: +49 \\ 7116891612.
}




\section{Notes}

The authors declare no competing financial interest.

\section{ACKNOWLEDGMENT}

This work was funded by the ERC starting grant (COFLeaf, grant number 639233). We gratefully acknowledge financial support by the Max Planck Society and the University of Munich (LMU) via the cluster of excellence Nanosystems Initiative Munich and the Center for Nanoscience (CeNS). We thank Christoph Hohmann, NIM, for providing the TOC image.

\section{REFERENCES}

1. Fujishima, A.; Honda, K., Electrochemical Photolysis of Water at a Semiconductor Electrode. Nature 1972, 238, 3738 .

2. Zhu, H.; Song, N.; Lv, H.; Hill, C. L.; Lian, T., Near Unity Quantum Yield of LightDriven Redox Mediator Reduction and Efficient $\mathrm{H}_{2}$ Generation Using Colloidal Nanorod Heterostructures. J. Am. Chem. Soc. 2012, 134, 11701-11708.

3. Kalisman, P.; Nakibli, Y.; Amirav, L., Perfect Photon-to-Hydrogen Conversion Efficiency. Nano Lett. 2016, 16, 1776-1781.

4. Liu, J.; Liu, Y.; Liu, N.; Han, Y.; Zhang, X.; Huang, H.; Lifshitz, Y.; Lee, S.-T.; Zhong, J.; Kang, Z., Metal-free efficient photocatalyst for stable visible water splitting via a two-electron pathway. Science 2015, 347, 970-974.

5. Zhang, G. G.; Lan, Z. A.; Lin, L. H.; Lin, S.; Wang, X. C., Overall water splitting by Pt/g$\mathrm{C}_{3} \mathrm{~N}_{4}$ photocatalysts without using sacrificial agents. Chem. Sci. 2016, 7, 3062-3066.

6. Fuel Cell Technologies Office Multi-Year Research, Development, and Demonstration (MYRD\&D) Plan, Office of Energy Efficiency \& Renewable Energy, U.S. Department of Energy,. 2015.

7. Moniz, S. J. A.; Shevlin, S. A.; Martin, D. J.; Guo, Z. X.; Tang, J. W., Visible-light driven heterojunction photocatalysts for water splitting a critical review. Energ Environ Sci 2015, 8, 731759.

8. Teets, T. S.; Nocera, D. G., Photocatalytic hydrogen production. Chem. Commun. 2011, 47, 9268-9274.

9. Artero, V.; Fontecave, M., Solar fuels generation and molecular systems: is it homogeneous or heterogeneous catalysis? Chem. Soc. Rev. 2013, 42, 2338-2356.

10. Xing, J.; Fang, W. Q.; Zhao, H. J.; Yang, H. G., Inorganic Photocatalysts for Overall Water Splitting. Chem. Asian J. 2012, 7, 642-657.

11. Osterloh, F. E., Inorganic nanostructures for photoelectrochemical and photocatalytic water splitting. Chem. Soc. Rev. 2013, 42, 22942320.

12. Wang, M.; Na, Y.; Gorlovb, M.; Sun, L., Light-driven hydrogen production catalysed by transition metal complexes in homogeneous systems. Dalton Trans. 2009, 6458-6467.

13. Bailar, J. C., Jr. , "Heterogenizing" Homogeneous Catalysts. Catal. Rev. 1974, 10, 17-36.

14. Lee, J.; Farha, O. K.; Roberts, J.; Scheidt, K. A.; Nguyen, S. T.; Hupp, J. T., Metal-organic framework materials as catalysts. Chem. Soc. Rev. 2009, 38, 1450-1459.

15. Thomas, J. M.; Raja, R.; Lewis, D. W., Single-Site Heterogeneous Catalysts. Angew. Chem. Int. Ed. 2005, 44, 6456-6482.

16. Wang, Z. J.; Ghasimi, S.; Landfester, K.; Zhang, K. A. I., A conjugated porous polybenzobisthiadiazole network for a visible lightdriven photoredox reaction. J. Mater. Chem. A 2014, 2, 18720.

17. Wang, Z. J.; Garth, K.; Ghasimi, S.; Landfester, K.; Zhang, K. A. I., Conjugated Microporous Poly(Benzochalcogenadiazole)s for Photocatalytic Oxidative Coupling of Amines under Visible Light. ChemSusChem 2015, 8, 3459-3464.

18. Wang, Z. J.; Ghasimi, S.; Landfester, K.; Zhang, K. A. I., Molecular Structural Design of Conjugated Microporous Poly(Benzooxadiazole) Networks for Enhanced Photocatalytic Activity with Visible Light. Adv. Mater. 2015, 27, 62656270 .

19. Hari, D. P.; Hering, T.; König, B., The Photoredox-Catalyzed Meerwein Addition Reaction:Intermolecular Amino-Arylation of Alkenes. Angew. Chem. Int. Ed. 2014, 53, 725728.

20. Hering, T.; Mühldorf, B.; Wolf, R.; König, $\quad$ B., $\quad$ Halogenase-Inspired OxidativeChlorination Using Flavin 
Photocatalysis. Angew. Chem. Int. Ed. 2016, 55, 5342-5345.

21. Hari, D. P.; König, B., Synthetic applications of eosin $\mathrm{Y}$ in photoredox catalysis. Chem. Commun. 2014, 50, 6688-6699.

22. Vyas, V. S.; Lotsch, B. V., Materials chemistry: Organic polymers form fuel from water. Nature 2015, 521, 41-2.

23. Kumar, S.; Wani, M. Y.; Arranja, C. T.; e Silva, J. d. A.; Avula, B.; Sobral, A. J. F. N., Porphyrins as nanoreactors in the carbon dioxide capture and conversion: a review. J. Mater. Chem. A 2015, 3, 19615-19637.

24. Merschjann, C.; Tschierlei, S.; Tyborski, T.; Kailasam, K.; Orthmann, S.; Hollmann, D.; Schedel-Niedrig, T.; Thomas, A.; Lochbrunner, S., Complementing Graphenes: 1D Interplanar Charge Transport in Polymeric Graphitic Carbon Nitrides. Adv. Mater. 2015, 27, 7993-7999.

25. Baxter, J. B.; Richter, C.; Schmuttenmaer, C. A., Ultrafast Carrier Dynamics in Nanostructures for Solar Fuels. Annu. Rev. Phys. Chem. 2014, 65, 423-447.

26. Calik, M.; Auras, F.; Salonen, L. M.; Bader, K.; Grill, I.; Handloser, M.; Medina, D. D.; Dogru, M.; Lobermann, F.; Trauner, D.; Hartschuh, A.; Bein, T., Extraction of Photogenerated Electrons and Holes from a Covalent Organic Framework Integrated Heterojunction. J. Am. Chem. Soc. 2014, 136, 17802-17807.

27. Roncali, J.; Leriche, P.; Blanchard, P., Molecular Materials for Organic Photovoltaics: Small is Beautiful. Adv. Mater. 2014, 26, 38213838 .

28. Eckenhoff, W. T.; Eisenberg, R., Molecular systems for light driven hydrogen production. Dalton Trans. 2012, 41, 1300413021.

29. Wang, Y.; Wang, X.; Antonietti, M., Polymeric Graphitic Carbon Nitride as a Heterogeneous Organocatalyst: From Photochemistry to Multipurpose Catalysis to Sustainable Chemistry. Angew. Chem. Int. Ed. 2012, 51, 68-89.

30. Zheng, Y.; Lin, L.; Wang, B.; Wang, X., Graphitic Carbon Nitride Polymers toward
Sustainable Photoredox Catalysis. Angew. Chem. Int. Ed. 2015, 54, 12868-12884.

31. Liu, A. Y.; Cohen, M. L., Prediction of New Low Compressibility Solids. Science 1989, 245, 841-842.

32. Teter, D. M.; Hemley, R. J., LowCompressibility Carbon Nitrides. Science 1996, 271, 53-55.

33. Maeda, K.; Wang, X.; Nishihara, Y.; Lu, D.; Antonietti, M.; Domen, K., Photocatalytic Activities of Graphitic Carbon Nitride Powder for Water Reduction and Oxidation under Visible Light. J. Phys. Chem. C 2009, 113, 4940-4947.

34. Wang, X.; Maeda, K.; Thomas, A.; Takanabe, K.; Xin, G.; Carlsson, J. M.; Domen, K.; Antonietti, M., A metal-free polymeric photocatalyst for hydrogen production from water under visible light. Nat. Mat. 2009, 8, 7680 .

35. Thomas, A.; Fischer, A.; Goettmann, F.; Antonietti, M.; Müller, J.-O.; Schlögl, R.; Carlsson, J. M., Graphitic carbon nitride materials: variation of structure and morphology and their use as metal-free catalysts. J. Mater. Chem. 2008, 18, 4893-4908.

36. Liebig, J., Uber einige Stickstoff Verbindungen. Ann. Pharm. 1834, 10, 1-47.

37. Schwarzer, A.; Saplinova, T.; Kroke, E., Tri-s-triazines (s-heptazines)_From a "mystery molecule" to industrially relevant carbon nitride materials. Coord. Chem. Rev. 2013, 257, 20322062.

38. Lotsch, B. V.; Döblinger, M.; Sehnert, J.; Seyfarth, L.; Senker, J.; Oeckler, O.; Schnick, W., Unmasking Melon by a Complementary Approach Employing Electron Diffraction, SolidState NMR Spectroscopy, and Theoretical Calculations - Structural Characterization of a Carbon Nitride Polymer. Chem. Eur. J. 2007, 13, 4969-4980.

39. Seyfarth, L.; Seyfarth, J.; Lotsch, B. V.; Schnick, W.; Senker, J., Tackling the stacking disorder of melon-structure elucidation in a semicrystalline material. Phys. Chem. Chem. Phys. 2010, 12, 2227-2237.

40. Tyborski, T.; Merschjann, C.; Orthmann, S.; Yang, F.; Lux-Steiner, M.-C.; SchedelNiedrig, T., Crystal structure of polymeric carbon 
nitride and the determination of its processtemperature-induced modifications. J. Phys.: Condens. Matter 2013, 25, 395402.

41. Fina, F.; Callear, S. K.; Carins, G. M.; Irvine, J. T. S., Structural Investigation of Graphitic Carbon Nitride via XRD and Neutron Diffraction. Chem. Mater. 2015, 27, 2612-2618.

42. Ham, Y.; Maeda, K.; Cha, D.; Takanabe, K.; Domen, K., Synthesis and Photocatalytic Activity of Poly(triazine imide). Chem. Asian J. 2013, 8, 218-224.

43. Schwinghammer, K.; Tuffy, B.; Mesch, M. B.; Wirnhier, E.; Martineau, C.; Taulelle, F.; Schnick, W.; Senker, J.; Lotsch, B. V., Triazinebased Carbon Nitrides for Visible-Light-Driven Hydrogen Evolution. Angew. Chem. Int. Ed. 2013, 52, 2435-2439.

44. Bhunia, M. K.; Yamauchi, K.; Takanabe, K., Harvesting Solar Light with Crystalline Carbon Nitrides for Efficient Photocatalytic Hydrogen Evolution. Angew. Chem. Int. Ed. 2014, 53, 11001-11005.

45. Schwinghammer, K.; Mesch, B.; Duppel, V.; Ziegler, C.; Senker, J. r.; Lotsch, B. V., Crystalline Carbon Nitride Nanosheets for Improved Visible-Light Hydrogen Evolution. $J$. Am. Chem. Soc. 2014, 136, 1730-1733.

46. Bhunia, M. K.; Melissen, S.; Parida, M. R.; Sarawade, P.; Basset, J.-M.; Anjum, D. H.; Mohammed, O. F.; Sautet, P.; Bahers, T. L.; Takanabe, K., Dendritic Tip-on PolytriazineBased Carbon Nitride Photocatalyst with High Hydrogen Evolution Activity. Chem. Mater. 2015, 27, 8237-8247.

47. Bojdys, M. J.; Müller, J.-O.; Antonietti, M.; Thomas, A., Ionothermal Synthesis of Crystalline, Condensed, Graphitic Carbon Nitride. Chem. Eur. J. 2008, 14, 8177-8182.

48. McMillan, P. F.; Lees, V.; Quirico, E.; Montagnac, G.; Sella, A.; Reynard, B.; Simon, P.; Bailey, E.; Deifallah, M.; Corà, F., Graphitic carbon nitride $\mathrm{C}_{6} \mathrm{~N}_{9} \mathrm{H}_{3} \cdot \mathrm{HCl}$ : Characterisation by UV and near-IR FT Raman spectroscopy. J. Solid State Chem. 2009, 182, 2670-2677.

49. Wirnhier, E.; Döblinger, M.; Gunzelmann, D.; Senker, J.; Lotsch, B. V.; Schnick, W., Poly(triazine imide) with Intercalation of Lithium and Chloride Ions $\left[\left(\mathrm{C}_{3} \mathrm{~N}_{3}\right)_{2}\left(\mathrm{NH}_{\mathrm{x}} \mathrm{Li}_{1-\mathrm{x}}\right)_{3} \cdot \mathrm{LiCl}\right]$ : $\mathrm{A}$
Crystalline 2D Carbon Nitride Network. Chem. Eur. J. 2011, 17, 3213-3221.

50. Huda, M. N.; Turner, J. A., Morphologydependent optical absorption and conduction properties of photoelectrochemical photocatalysts for $\mathrm{H}_{2}$ production: A case study. J. Appl. Phys. 2010, 107, 123703.

51. Chen, X.; Jun, Y.-S.; Takanabe, K.; Maeda, K.; Domen, K.; Fu, X.; Antonietti, M.; Wang, X., Ordered Mesoporous SBA-15 Type Graphitic Carbon Nitride: A Semiconductor Host Structure for Photocatalytic Hydrogen Evolution with Visible Light. Chem. Mater. 2009, 21, 40934095.

52. Zhang, J.; Chen, X.; Takanabe, K.; Maeda, K.; Domen, K.; Epping, J. D.; Fu, X.; Antonietti, M.; Wang, X., Synthesis of a Carbon Nitride Structure for Visible-Light Catalysis by Copolymerization. Angew. Chem. Int. Ed. 2010, 49, 441-444.

53. Liu, G.; Niu, P.; Sun, C.; Smith, S. C.; Chen, Z.; Lu, G. Q. M.; Cheng, H.-M., Unique Electronic Structure Induced High Photoreactivity of Sulfur-Doped Graphitic $\mathrm{C}_{3} \mathrm{~N}_{4}$. J. Am. Chem. Soc. 2010, 132, 11642-11648.

54. Zhao, Z.; Sun, Y.; Dong, F., Graphitic carbon nitride based nanocomposites: a review. Nanoscale 2015, 7, 15-37.

55. Niu, P.; Zhang, L.; Liu, G.; Cheng, H.-M., Graphene-Like Carbon Nitride Nanosheets for Improved Photocatalytic Activities. Adv. Funct. Mater. 2012, 22, 2763-4770.

56. Shalom, M.; Inal, S.; Fettkenhauer, C.; Neher, D.; Antonietti, M., Improving Carbon Nitride Photocatalysis by Supramolecular Preorganization of Monomers. J. Am. Chem. Soc. 2013, 135, 7118-7121.

57. Caputo, C. A.; Gross, M. A.; Lau, V. W.; Cavazza, C.; Lotsch, B. V.; Reisner, E., Photocatalytic Hydrogen Production using Polymeric Carbon Nitride with a Hydrogenase and a Bioinspired Synthetic Ni Catalyst. Angew. Chem. Int. Ed. 2014, 53, 11538-11542.

58. Cao, S.-W.; Liu, X.-F.; Yuan, Y.-P.; Zhang, Z.-Y.; Fang, J.; Loo, S. C. J.; Barber, J.; Sum, T. C.; Xue, C., Artificial photosynthetic hydrogen evolution over $\mathrm{g}-\mathrm{C}_{3} \mathrm{~N}_{4}$ nanosheets 
coupled with cobaloxime. Phys. Chem. Chem. Phys. 2013, 15, 18363-18366.

59. Wang, D.; Zhang, Y.; Chen, W., A novel nickel-thiourea-triethylamine complex adsorbed on graphitic $\mathrm{C}_{3} \mathrm{~N}_{4}$ for low-cost solar hydrogen production. Chem. Commun. 2014, 50, 17541756.

60. Cao, S.-W.; Yuan, Y.-P.; Barber, J.; Loo, S. C. J.; Xue, C., Noble-metal-free g$\mathrm{C}_{3} \mathrm{~N}_{4} / \mathrm{Ni}(\mathrm{dmgH})_{2}$ composite for efficient photocatalytic hydrogen evolution under visible light irradiation. Appl. Surf. Sci. 2014, 319, 344349.

61. Martin, D. J.; Qiu, K.; Shevlin, S. A.; Handoko, A. D.; Chen, X.; Guo, Z.; Tang, J., Highly Efficient Photocatalytic $\mathrm{H}_{2}$ Evolution from Water using Visible Light and StructureControlled Graphitic Carbon Nitride. Angew. Chem. Int. Ed. 2014, 53, 9240-9245.

62. Butchosa, C.; Guiglion, P.; Zwijnenburg, M. A., Carbon Nitride Photocatalysts for Water Splitting: A Computational Perspective. J. Phys. Chem. C 2014, 118, 24833-24842.

63. Lau, V. W.-h.; Moudrakovski, I.; Botari, T.; Weinburger, S.; Mesch, M. B.; Duppel, V.; Senker, J.; Blum, V.; Lotsch, B. V., Towards rational design of carbon nitride photocatalysts: Identification of cyanamide "defects" as catalytically relevant sites. Nat. Commun. 2016, Accepted.

64. Yanagida, S.; Kabumoto, A.; Mizumoto, K.; Pac, C.; Yoshino, K., Poly(p-phenylene)catalysed photoreduction of water to hydrogen. $J$. Chem. Soc., Chem. Commun. 1985, 474-475.

65. Kovacic, P.; Kyriakis, A., Polymerization of Benzene to p-Polyphenyl by Aluminum Chloride-Cupric Chloride. J. Am. Chem. Soc. 1963, 85, 454-458.

66. Shibata, T.; Kabumoto, A.; Shiragami, T.; Ishitani, O.; Pac, C.; Yanagida, S., Novel visiblelight-driven photocatalyst. Poly(p-phenylene)catalyzed photoreductions of water, carbonyl compounds, and olefins. J. Phys. Chem. 1990, 94, 2068-2076.

67. Matsuoka, S.; Kohzuki, T.; Nakamura, A.; Pac, C.; Yanagida, S., Efficient visible-lightdriven photocatalysis. Poly(pyridine-2,5-diyl)catalysed hydrogen photoevolution and photoreduction of carbonyl compounds. J. Chem. Soc., Chem. Commun. 1991, 580-581.

68. Matsuoka, S.; Kohzuki, T.; Kuwana, Y.; Nakamura, A.; Yanagida, S., Visible-LightInduced Photocatalysis of Poly(Pyridine-2,5Diyl) - Photoreduction of Water, CarbonylCompounds and Alkenes with Triethylamine. $J$. Chem. Soc. Perkin Trans. 2 1992, 679-685.

69. Yanagida, S.; Ogata, T.; Kuwana, Y.; Wada, Y.; Murakoshi, K.; Ishida, A.; Takamuku, S.; Kusaba, M.; Nakashima, N., Synthesis of $2,2^{\prime}: 5^{\prime}, 2^{\prime \prime}$-terpyridine and 2,2':5',2":5",2"'quaterpyridine and their photocatalysis of the reduction of water. J. Chem. Soc. Perk. Trans. 2 1996, 1963-1969.

70. Matsuoka, S.; Fujii, H.; Yamada, T.; Pac, C.; Ishida, A.; Takamuku, S.; Kusaba, M.; Nakashima, N.; Yanagida, S.; Hashimoto, K.; Sakata, T., Photocatalysis of Oligo(ParaPhenylenes) - Photoreductive Production of Hydrogen and Ethanol in Aqueous Triethylamine. J. Phys. Chem. 1991, 95, 5802-5808.

71. Matsuoka, S.; Kohzuki, T.; Pac, C.; Yanagida, S., Photochemical reduction of carbon dioxide to formate catalyzed by $\mathrm{p}$-terphenyl in aprotic polar solvent. Chem. Lett. 1990, 20472048.

72. Matsuoka, S.; Yamamoto, K.; Ogata, T.; Kusaba, M.; Nakashima, N.; Fujita, E.; Yanagida, S., Efficient and Selective Electron Mediation of Cobalt Complexes with Cyclam and Related Macrocycles in the p-Terphenyl-Catalyzed Photoreduction of $\mathrm{CO}_{2}$. J. Am. Chem. Soc. 1993, 115, 601-609.

73. Ogata, T.; Yanagida, S.; Brunschwig, B. S.; Fujita, E., Mechanistic and Kinetic-Studies of Cobalt Macrocycles in a Photochemical $\mathrm{CO}_{2}$ Reduction System - Evidence of $\mathrm{Co}-\mathrm{CO}_{2}$ Adducts as Intermediates. J. Am. Chem. Soc. 1995, 117, 6708-6716.

74. Sprick, R. S.; Jiang, J. X.; Bonillo, B.; Ren, S. J.; Ratvijitvech, T.; Guiglion, P.; Zwijnenburg, M. A.; Adams, D. J.; Cooper, A. I., Tunable Organic Photocatalysts for VisibleLight-Driven Hydrogen Evolution. J. Am. Chem. Soc. 2015, 137, 3265-3270.

75. Sprick, R. S.; Bonillo, B.; Clowes, R.; Guiglion, P.; Brownbill, N. J.; Slater, B. J.; Blanc, 
F.; Zwijnenburg, M. A.; Adams, D. J.; Cooper, A. I., Visible-Light-Driven Hydrogen Evolution Using Planarized Conjugated Polymer Photocatalysts. Angew Chem Int Ed Engl 2016, 55, 1792-6.

76. Yan, H.; Huang, Y., Polymer composites of carbon nitride and poly(3-hexylthiophene) to achieve enhanced hydrogen production from water under visible light. Chem. Commun. 2011, 47, 4168-4170.

77. Sui, Y.; Liu, J.; Zhang, Y.; Tian, X.; Chen, W., Dispersed conductive polymer nanoparticles on graphitic carbon nitride for enhanced solardriven hydrogen evolution from pure water. Nanoscale 2013, 5, 9150-9155.

78. Xu, Y. H.; Jin, S. B.; Xu, H.; Nagai, A.; Jiang, D. L., Conjugated microporous polymers: design, synthesis and application. Chem. Soc. Rev. 2013, 42, 8012-8031.

79. Schwab, M. G.; Hamburger, M.; Feng, X.; Shu, J.; Spiess, H. W.; Wang, X.; Antonietti, M.; Mullen, K., Photocatalytic hydrogen evolution through fully conjugated poly(azomethine) networks. Chem. Commun. 2010, 46, 8932-8934. 80. Katekomol, P.; Roeser, J.; Bojdys, M.; Weber, J.; Thomas, A., Covalent Triazine Frameworks Prepared from 1,3,5Tricyanobenzene. Chem. Mater. 2013, 25, 15421548.

81. Kuhn, P.; Antonietti, M.; Thomas, A., Porous, Covalent Triazine-Based Frameworks Prepared via Ionothermal Synthesis Angew. Chem. Int. Ed. 2008, 47, 3450-3453.

82. Ren, S.; Bojdys, M. J.; Dawson, R.; Laybourn, A.; Khimyak, Y. Z.; Adams, D. J.; Cooper, A. I., Porous, Fluorescent, Covalent Triazine-Based Frameworks Via RoomTemperature and Microwave-Assisted Synthesis Adv. Mater. 2012, 24, 2357-2361.

83. Bojdys, M. J.; Jeromenok, J.; Thomas, A.; Antonietti, M., Rational extension of the family of layered, covalent, triazine based frameworks with regular porosity. Adv. Mater. 2010, 22, 22022205.

84. Hug, S.; Tauchert, M. E.; Li, S.; Pachmayr, U. E.; Lotsch, B. V., A functional triazine framework based on $\mathrm{N}$-heterocyclic building blocks. J. Mater. Chem. 2012, 22, 13956-13964.

85. See, K. A.; Hug, S.; Schwinghammer, K.; Lumley, M. A.; Zheng, Y.; Nolt, J. M.; Stucky, G. D.; Wudl, F.; Lotsch, B. V.; Seshadri, R., Lithium Charge Storage Mechanisms of Cross-Linked Triazine Networks and Their Porous Carbon Derivatives. Chem. Mater. 2015, 27, 3821-3829.

86. Hug, S.; Stegbauer, L.; Oh, H.; Hirscher, M.; Lotsch, B. V., Nitrogen-Rich Covalent Triazine Frameworks as High-Performance Platforms for Selective Carbon Capture and Storage. Chem. Mater. 2015, 27, 8001-8010.

87. Butchosa, C.; McDonald, T. O.; Cooper, A. I.; Adams, D. J.; Zwijnenburg, M. A., Shining a Light on s-Triazine-Based Polymers. J. Phys. Chem. C 2014, 118, 4314-4324.

88. Jiang, X.; Wang, P.; Zhao, J., 2D covalent triazine framework: a new class of organic photocatalyst for water splitting. J. Mater. Chem. A 2015, 3, 7750-7758.

89. Bi, J.; Fang, W.; Li, L.; Wang, J.; Liang, S.; He, Y.; Liu, M.; Wu, L., Covalent TriazineBased Frameworks as Visible Light Photocatalysts for the Splitting of Water. Macromol. Rapid Commun. 2015, 36, 1799-1805. 90. Schwinghammer, K.; Hug, S.; Mesch, M. B.; Senker, J.; Lotsch, B. V., Phenyl-triazine oligomers for light-driven hydrogen evolution. Energ Environ Sci 2015, 8, 3345-3353.

91. Lau, V. W.-h.; Mesch, M. B.; Duppel, V.; Blum, V.; Senker, J.; Lotsch, B. V., Low molecular-weight carbon nitrides for solar hydrogen evolution. J. Am. Chem. Soc. 2015, 137, 1064-1072.

92. Jiang, X.; Wang, P.; Zhao, J., 2D covalent triazine framework: a new class of organic photocatalyst for water splitting. J. Mater. Chem. A 2015, 3, 7750-7758.

93. Cote, A. P.; Benin, A. I.; Ockwig, N. W.; O'Keeffe, M.; Matzger, A. J.; Yaghi, O. M., Porous, crystalline, covalent organic frameworks. Science 2005, 310, 1166-1170.

94. Spitler, E. L.; Koo, B. T.; Novotney, J. L.; Colson, J. W.; Uribe-Romo, F. J.; Gutierrez, G. D.; Clancy, P.; Dichtel, W. R., A 2D Covalent Organic Framework with 4.7-nm Pores and 
Insight into Its Interlayer Stacking. J. Am. Chem. Soc. 2011, 133, 19416-19421.

95. Spitler, E. L.; Colson, J. W.; Uribe-Romo, F. J.; Woll, A. R.; Giovino, M. R.; Saldivar, A.; Dichtel, W. R., Lattice Expansion of Highly Oriented 2D Phthalocyanine Covalent Organic Framework Films. Angew. Chem. Int. Ed. 2012, 51, 2623-2627.

96. Furukawa, H.; Yaghi, O. M., Storage of Hydrogen, Methane, and Carbon Dioxide in Highly Porous Covalent Organic Frameworks for Clean Energy Applications. J. Am. Chem. Soc. 2009, 131, 8875-8883.

97. Feng, X.; Ding, X. S.; Jiang, D., Covalent organic frameworks. Chem. Soc. Rev. 2012, 41, 6010-6022.

98. Uribe-Romo, F. J.; Doonan, C. J.; Furukawa, H.; Oisaki, K.; Yaghi, O. M., Crystalline Covalent Organic Frameworks with Hydrazone Linkages. J. Am. Chem. Soc. 2011, 133, 11478-11481.

99. Dalapati, S.; Jin, S.; Gao, J.; Xu, Y.; Nagai, A.; Jiang, D., An azine-linked covalent organic framework. J. Am. Chem. Soc. 2013, 135, 17310-3.

100. Kandambeth, S.; Mallick, A.; Lukose, B.; Mane, M. V.; Heine, T.; Banerjee, R., Construction of Crystalline 2D Covalent Organic Frameworks with Remarkable Chemical (Acid/Base) Stability via a Combined Reversible and Irreversible Route. J. Am. Chem. Soc. 2012, 134, 19524-19527.

101. Kandambeth, S.; Shinde, D. B.; Panda, M. K.; Lukose, B.; Heine, T.; Banerjee, R., Enhancement of chemical stability and crystallinity in porphyrin-containing covalent organic frameworks by intramolecular hydrogen bonds. Angew. Chem. Int. Ed. 2013, 52, 13052-6. 102. DeBlase, C. R.; Silberstein, K. E.; Truong, T.-T.; Abruña, H. D.; Dichtel, W. R., $\beta$ Ketoenamine-Linked Covalent Organic Frameworks Capable of Pseudocapacitive Energy Storage. J. Am. Chem. Soc. 2013, 135, 1682116824.

103. Jin, S. B.; Ding, X. S.; Feng, X.; Supur, M.; Furukawa, K.; Takahashi, S.; Addicoat, M.; El-Khouly, M. E.; Nakamura, T.; Irle, S.; Fukuzumi, S.; Nagai, A.; Jiang, D. L., Charge
Dynamics in A Donor-Acceptor Covalent Organic Framework with Periodically Ordered Bicontinuous Heterojunctions. Angew. Chem. Int. Ed. 2013, 52, 2017-2021.

104. Jin, S. B.; Sakurai, T.; Kowalczyk, T.; Dalapati, S.; Xu, F.; Wei, H.; Chen, X.; Gao, J.; Seki, S.; Irle, S.; Jiang, D. L., Two-Dimensional Tetrathiafulvalene Covalent Organic Frameworks: Towards Latticed Conductive Organic Salts. Chem Eur. J. 2014, 20, 1460814613.

105. Jin, S.; Supur, M.; Addicoat, M.; Furukawa, K.; Chen, L.; Nakamura, T.; Fukuzumi, S.; Irle, S.; Jiang, D., Creation of Superheterojunction Polymers via Direct Polycondensation: Segregated and Bicontinuous Donor-Acceptor pi-Columnar Arrays in Covalent Organic Frameworks for Long-Lived Charge Separation. J. Am. Chem. Soc. 2015, 137, 781727.

106. Dogru, M.; Handloser, M.; Auras, F.; Kunz, T.; Medina, D.; Hartschuh, A.; Knochel, P.; Bein, T., A Photoconductive ThienothiopheneBased Covalent Organic Framework Showing Charge Transfer Towards Included Fullerene. Angew. Chem. Int. Ed. 2013, 52, 2920-2924.

107. Nagai, A.; Chen, X.; Feng, X.; Ding, X. S.; Guo, Z. Q.; Jiang, D. L., A Squaraine-Linked Mesoporous Covalent Organic Framework. Angew. Chem. Int. Ed. 2013, 52, 3770-3774.

108. Stegbauer, L.; Schwinghammer, K.; Lotsch, B. V., A hydrazone-based covalent organic framework for photocatalytic hydrogen production. Chem. Sci. 2014, 5, 2789-2793.

109. Bunck, D. N.; Dichtel, W. R., Bulk Synthesis of Exfoliated Two-Dimensional Polymers Using Hydrazone-Linked Covalent Organic Frameworks. J. Am. Chem. Soc. 2013, 135, 14952-14955.

110. Thote, J.; Aiyappa, H. B.; Deshpande, A.; Diaz Diaz, D.; Kurungot, S.; Banerjee, R., A covalent organic framework-cadmium sulfide hybrid as a prototype photocatalyst for visiblelight-driven hydrogen production. Chem. Eur. J. 2014, 20, 15961-5.

111. Vyas, V. S.; Haase, F.; Stegbauer, L.; Savasci, G.; Podjaski, F.; Ochsenfeld, C.; Lotsch, B. V., A tunable azine covalent organic 
framework platform for visible light-induced hydrogen generation. Nat. Commun. 2015, 6, 8508 .

112. Banerjee, M.; Shukla, R.; Rathore, R., Synthesis, Optical, and Electronic Properties of Soluble Poly-p-phenylene Oligomers as Models for Molecular Wires. J. Am. Chem. Soc. 2009, 131, 1780-1786.

113. Guiglion, P.; Butchosa, C.; Zwijnenburg, M. A., Polymeric watersplitting photocatalysts; a computational perspective on the water oxidation conundrum. J. Mater. Chem. A 2014, 2, 1199612004.

114. Guiglion, P.; Butchosa, C.; Zwijnenburg, M. A., Polymer Photocatalysts for Water Splitting: Insights from Computational Modeling. Macromol. Chem. Phys. 2016, 217, 344-353. 